ARTAZA, Osvaldo. "La utilidad del concepto de corrupción de cara a la delimitación de la conducta típica en el delito de cohecho".

Polít. crim. Vol. 11, № 21 (Julio 2016), Art. 11, pp. 307-339.

[http://www.politicacriminal.cl/Vol_11/n_21/Vol11N21A11.pdf]

\title{
La utilidad del concepto de corrupción de cara a la delimitación de la conducta típica en el delito de cohecho
}

\section{The usefulness of the concept of corruption regarding the delimitation of the typical behavior in the crime of bribery}

\author{
Osvaldo Artaza Varela ${ }^{1}$ \\ Doctor en Derecho. Profesor Universidad de Talca \\ oartaza@utalca.cl
}

\begin{abstract}
Resumen
El objeto de este artículo es ofrecer criterios para delimitar el concepto de corrupción, y presentar una primera aproximación de su potencial utilidad para la interpretación de la conducta típica del delito de cohecho tipificado en los artículos 248 y ss. del Código penal chileno. Para esto se entenderá la corrupción como una forma particular de agresión a intereses penalmente relevantes. Se ahondará en sus principales elementos con el propósito de detectar una serie de aspectos problemáticos relativos a la conducta delictiva del delito de cohecho que podrían ser solucionados a través de ciertos criterios otorgados por el concepto de corrupción.
\end{abstract}

Palabras clave: Corrupción, cohecho, soborno, conducta típica.

\begin{abstract}
The purpose of this article is to provide criteria for delimiting the concept of corruption, and present a first approximation of its potential usefulness for the interpretation of the typical behavior of the crime of bribery described in articles 248 et seq. of the Chilean Penal Code. For this purpose, corruption shall be understood as a particular form of aggression to criminally relevant interests. Its main components will be examined in order to detect a number of problematic aspects of the criminal conduct of bribery that could be solved through the criteria provided by the concept of corruption.
\end{abstract}

Key words: Corruption, bribe, bribery, criminal behavior.

\footnotetext{
${ }^{1}$ El presente artículo se enmarca en el proyecto de investigación FONDECYT $\mathrm{N}^{\circ} 1150148$ titulado "Corrupción y actividad empresarial. Análisis conceptual para una nueva sistematización", cuyo investigador responsable es el Dr. Raúl Carnevali Rodríguez. Se agradece la colaboración de los Sres. ayudantes Sebastián Galleguillos Agurto, Luciano Rojas Morán y Gabriel Silva-Riesco, por sus valiosos aportes en el desarrollo del artículo.
} 
ARTAZA, Osvaldo. "La utilidad del concepto de corrupción de cara a la delimitación de la conducta típica en el delito de cohecho".

\section{Presentación del problema: Dificultades para la delimitación del concepto de corrupción.}

Abordar el problema de la corrupción supone precisar no solo el concepto desde el que se parte, sino que también el lugar desde el que se está analizando, sobre todo si se trata de un concepto que suele ser abordado por diversas disciplinas ${ }^{2}$. Así, por ejemplo, un economista colocará su atención en los efectos que la corrupción pueda causar en el desarrollo económico de un país o en las consecuencias que puedan derivar para la competencia en el ámbito de las transacciones económicas internacionales. A su vez, un criminólogo podría ahondar en las causas de la corrupción como fenómeno delictivo o en la descripción de los criterios con los cuales en una sociedad se define un comportamiento como corrupto, y en la constatación de diferencias culturales asociadas a tal definición.

En nuestro caso, es decir, para las ciencias jurídico penales, se debe partir por reconocer que el impacto del fenómeno analizado es evidente ${ }^{3}$. Basta, para corroborar tal relevancia, observar los instrumentos internacionales más relevantes en esta materia que exigen o sugieren, justamente, la criminalización de una serie de conductas lesivas definidas como actos de corrupción ${ }^{4}$.

Con todo, tal aclaración relativa al punto de partida no tiene mucho sentido si no se clarifica de qué se está hablando, es decir, qué se entenderá por corrupción. Suele reconocerse que el concepto de corrupción es complejo de delimitar debido a múltiples motivos $^{5}$. Tal dificultad estaría asociada principalmente al alcance del mismo, es decir, a la delimitación de aquello que podamos incluir en la categoría de "actos de corrupción".

\footnotetext{
${ }^{2}$ En relación al interés mostrado desde las ciencias sociales, ver LOWENSTEIN, Daniel H., "Political Bribery and the Intermediate Theory of Politics", UCLA Law Review, Vol. 32 (1984-85), pp. 799 y ss.

${ }^{3}$ En nuestro país, RODRÍGUEZ COLLAO, José Luis, "Delimitación del concepto penal de corrupción”, Revista de Derecho de la Pontificia Universidad Católica de Valparaíso, XXV (2004), p. 340, incluso parece sostener una especie de "concepto penal de corrupción" que refleja esta necesidad de delimitar el concepto amplio representativo del fenómeno social por uno más restringido. Ver también, en relación a las dificultades que se pueden presentar a propósito del traslado de la corrupción del ámbito fenomenológico al legal, ALCALE SÁNCHEZ, María, "La lucha contra la corrupción en el ámbito supranacional y su incidencia en el código penal español", Diritto Penale Contemporaneo, 3-4 (2014), pp. 25 y ss., disponible en web: http://www.penalecontemporaneo.it/foto/3364DPC_Trim_3-4_2014.pdf [visitado el 29.12.2015].

${ }^{4}$ Al respecto, DE LA CUESTA ARZAMENDI, José Luis, "La corrupción ante el Derecho y la Justicia", Diario La Ley, N 8153, 2013, p. 3.

${ }^{5}$ Es representativo, entre nosotros, el trabajo de BALMACEDA, Gustavo; CASTRO, Carlos, Corrupción y delitos contra la administración pública. Especial referencia a los delitos de malversación de caudales y fraude al fisco, Santiago: Librotecnia, 2015, pp. 17 y ss. Sin embargo, no parece correcto que tal dificultad de ofrecer un concepto unívoco responda a la multisectorialidad con la que se ha analizado este concepto. Tal propiedad incide más bien en los diversos matices con los que se aborda el fenómeno, y el foco de atención colocado por cada una de tales disciplinas. Que diversas disciplinas analicen un concepto desde diversos ángulos no es incompatible al hecho de que estén refiriéndose a un mismo fenómeno y no a cualquier otro. Por lo mismo, se puede sostener que la falta de univocidad al respecto responde a otro factor, este es, el de los problemas de indeterminación del lenguaje. Al respecto resulta fundamental lo señalado por RODRÍGUEZ COLLAO, "Delimitación", cit. nota $\mathrm{n}^{\circ}$ 3, pp. 343 y ss., identificando una serie de intentos de definición que provienen desde las ciencias sociales. La doctrina comparada, por lo general, efectúa el mismo diagnóstico, ver CARUSO FONTÁN, María Viviana, "El concepto de corrupción. Su evolución hacia un nuevo delito de fraude en el deporte como forma de corrupción en el sector privado", Foro, Nueva Época, n 9 (2009), p. 146;
} 
Polít. crim. Vol. 11, No 21 (Julio 2016), Art. 11, pp. 307-339.

[http://www.politicacriminal.cl/Vol_11/n_21/Vol11N21A11.pdf]

Como se intentará demostrar, estos problemas de delimitación tienen que ver principalmente con la vaguedad del término. Por tanto, con el objeto de clarificar aún más el problema planteado, es necesario tener en cuenta algunas consideraciones previas. Como explica Martínez Zorrilla, en nuestro uso del lenguaje en ocasiones nos vemos enfrentados a ciertos fenómenos que "pueden dar lugar a algunas dificultades, impidiéndonos saber con exactitud o seguridad cuál es el significado de ciertas expresiones ${ }^{6}$ ". Una de tales dificultades sería la de la vaguedad.

Tal dificultad estaría asociada al "significado de las palabras" consistente en que la misma resulta indeterminada en sus límites (es decir, en la connotación del mismo), por lo que resultaría difícil "determinar con precisión si un objeto cae dentro o fuera de su denotación ${ }^{7}$ ". Como se podrá apreciar, al momento de concretar tal concepto nos enfrentamos a un problema interpretativo relacionado al uso que hacemos de este término ${ }^{8}$.

En este sentido resulta necesario, para poder ofrecer una propuesta de concreción del término, detectar el motivo de tal vaguedad. Como señala Kindhäuser, este concepto es usado, atendiendo a su sentido literal, como sinónimo de decadencia y perversión moral ${ }^{9}$. En un sentido similar Lombana Villalba sostiene que "desde el punto de vista gramatical, el término corrupción se refiere a un fenómeno de desnaturalización o desviación de ciertos

DE LA CUESTA ARZAMENDI, José Luis, "Iniciativas Internacionales contra la corrupción", Eguzkilore, N ${ }^{\circ}$ 17 (2003), pp. 7 y ss. Una mejor forma de expresar esta dificultad se encuentra descrita por BURKE, Thomas, "The concept of corruption in campaign finance law", Constitucional Commentary, Vol. 14 (1997), p. 129, quien critica una conocida clasificación de la aproximación a la definición de este concepto por no resultar satisfactoria. Esta clasificación atendería a si para la definición imperan aspectos legales o normativos, la opinión pública o el interés público. En la primera aproximación lo relevante sería detectar qué es lo que la ley define como corrupto, en la segunda, aquello que la mayoría de las personas considerarían como corrupto y, por último, la tercera, caracterizada por la definición de ciertos ideales contra los cuales la conducta corrupta se pueda evaluar (esto es, sería un criterio negativo).

${ }^{6} \mathrm{Al}$ respecto ver, MARTÍNEZ ZORILLA, David, Metodología jurídica y argumentación, Madrid, Barcelona, Buenos Aires, Sao Paulo: Marcial Pons, 2013, p.57.

${ }^{7}$ MARTÍNEZ ZORILLA, Metodología jurídica y argumentación, cit. nota $n^{\circ}$ 6, p. 57. De acuerdo a lo señalado por el autor, la "denotación de un término es el conjunto de objetos designados por el término (por ejemplo, la denotación de «silla» sería el conjunto de todas las sillas, esto es, de todos los objetos que son calificables como «silla»). Por su parte, la connotación de «silla» estaría formada por el conjunto de propiedades que hacen que cierto objeto sea calificable como «silla»: entre otras, que sea un objeto apto para sentarse, que esté pensado para una sola persona, etc.)".

${ }^{8}$ Es necesario hacer una precisión al respecto. Al referirme a problemas interpretativos no lo hago todavía en relación a eventuales problemas de vaguedad de algún tipo penal en particular, sino como un problema general del uso del lenguaje. No obstante, la asignación de un sentido o la propuesta de un enunciado equivalente o sinónimo de "corrupción" resultaría necesario en la medida que se pretenda dar cuenta de los diversos instrumentos internacionales cuyo propósito es justamente la criminalización de conductas que deben ser comprendidas como "actos de corrupción". Por lo mismo, y como se defenderá más adelante, el contenido que se le asigne al concepto resultará fundamental para delimitar la conducta típica en los tipos penales cuya conducta típica pueda ser incluida, en definitiva, en la categoría objeto de estudio.

${ }^{9}$ Al respecto, véase KINDHÄUSER, Urs, "Presupuestos de la corrupción punible en el Estado, la economía, y la sociedad. Los delitos de corrupción en el Código Penal Alemán. Los delitos de corrupción en el Código penal alemán", Trad. GARCÍA CAVERO, Percy, Política Criminal, n 3 (2007), A1, pp. 1-18, disponible en web: http://www.politicacriminal.cl/n_03/a_1_3.pdf [visitado el 28.12.2015]. Ver también, HOLMES, Leslie, Corruption. A very short introduction, Oxford: Oxford University Press, 2015, p. 1. 
ARTAZA, Osvaldo. "La utilidad del concepto de corrupción de cara a la delimitación de la conducta típica en el delito de cohecho".

parámetros de comportamiento ${ }^{10}$ ". Tal punto de partida supone, siguiendo a Burke, la definición de un estado ideal, ya que es justamente tal estado lo que se descompone o degrada $^{11}$. Si se observa adecuadamente lo anteriormente señalado, se entiende que el problema de indeterminación esté dado porque este término estaría asociado a una evidente dimensión evaluativa o valorativa ${ }^{12}$. No se puede llamar a algo corrupto sin una referencia implícita a algún ideal y a la decisión de cuándo se altera o desnaturaliza el mismo.

Como se podrá apreciar a lo largo de este artículo, la indeterminación del concepto estudiado vendría dado justamente por las dificultades asociadas a la concreción de cómo y cuándo tales pautas ideales correlativas se degenerarían o desnaturalizarían.

Ahora, para la resolución de tales problemas conviene considerar lo sostenido por Guastini, quien parte de la base que la vaguedad es una característica de los predicados del lenguaje natural $^{13}$. Para analizar el significado de tales predicados se recurriría a dos componentes diversos. Por una parte al "sentido" (o intención), esto es, a la respuesta al "qué quiere decir", y que define como "el conjunto de los atributos que un objeto debe tener para que el predicado pueda serle aplicado", así como a la "referencia" (a la que llama también "extensión"), esto es, a la respuesta de a qué se refiere, y que define como "la clase de objetos que presentan tales atributos y a los cuales el predicado les es por tanto aplicable" Como señala este autor, la referencia siempre dependerá del sentido y, por ende, "cuanto menos preciso sea el sentido, tanto más extensa será la referencia y viceversa ${ }^{15}$.

${ }^{10}$ LOMBANA VILLALBA, Jaime, "La tipificación del tráfico de influencias y del cohecho en España y en
Colombia como forma de prevención de la corrupción pública", Tesis Doctoral, Universidad de León, 2013,
p. $\quad$ disponible https://buleria.unileon.es/bitstream/handle/10612/3274/tesis 498b6e.PDF?sequence=1 [visitado el 28.12.2015]. Ver además, BURKE, “The concept”, cit. nota ${ }^{\circ}$ 3, p. 128. De acuerdo a este autor, de todas las definiciones básicas de éste se puede extraer un elemento que es común a todas ellas, esto es la noción de que "algo puro, natural u ordenado ha decaído o se ha degradado"; GRIFFIN, Lisa Kern, "The Federal Common Law Crime of Corruption”, North Carolina Law Review, Vol. 89 (2011), pp.1825 y ss. Ver también, entre nosotros RODRÍGUEZ COLLAO, "Delimitación”, cit. nota n 3, pp. 341 y ss. Al respecto, CARASSALE, Santiago, “Corrupción”, Eunomía. Revista en Cultura de a Legalidad, No 4 (2013), p. 173.

${ }^{11}$ Se debe advertir, eso sí, que si bien es cierto que de la aproximación descrita se podría desprender que lo nuclear de la corrupción es un resultado, es decir, la constatación de que un estado ideal de cosas se ha desnaturalizado (o corrompido), en el ámbito jurídico la definición de la misma tiene como foco el de delimitar el comportamiento corrupto. Tales esfuerzos están encaminados a detectar aquel margen de conductas que, justamente, desnaturalicen o corrompan ciertas pautas ideales que sean especialmente relevantes para los diversos ordenamientos jurídicos locales que puedan ser definidas como actos de corrupción.

${ }^{12}$ Al respecto, MARTÍNEZ ZORILLA, Metodología jurídica y argumentación, cit. nota $\mathrm{n}^{\circ}$ 6, pp. 61-62, señala que se trataría de un concepto dotado de una fuerte "carga emotiva" es decir, aquel aspecto de una expresión relativo a su "dimensión evaluativa o valorativa" y que resultaría "inseparable del significado de la expresión".

${ }^{13}$ GUASTINI, Ricardo, Interpretar y argumentar, Trad. ÁLVAREZ MEDINA, Silvana, Madrid: Centro de Estudios Políticos y Constitucionales, 2014, pp. 68 y ss.

${ }^{14}$ El ejemplo para clarificar tal distinción del autor es el siguiente: “...el sentido de «planeta» es (grosso modo) cuerpo celeste opaco que gira alrededor de una estrella; su referencia es a todos los cuerpos celestes opacos que giran alrededor de una estrella (Venus, Marte, Tierra, etc., pero no Luna)". Al respecto, GUASTINI, Interpretar y argumentar, cit. nota $\mathrm{n}^{\circ} 13$, p. 69.

${ }^{15}$ De acuerdo al autor, “... todos los predicados tienen una referencia dudosa, o «abierta» (open textured), y en este sentido se ven afectados por la vaguedad extensional. Por otro lado, la vaguedad extensional depende 
Polít. crim. Vol. 11, No 21 (Julio 2016), Art. 11, pp. 307-339.

[http://www.politicacriminal.cl/Vol_11/n_21/Vol11N21A11.pdf]

Lo anteriormente señalado es fundamental para concretar el propósito de este trabajo, ya que lo que se intentará ahora es ofrecer una delimitación del concepto de corrupción. Para tales efectos, se deberán detectar aquellos problemas relativos al sentido, o al qué queremos decir cuando usamos este concepto. Es decir, cuáles serían esta serie de atributos que debe presentar una conducta para que podamos atribuirle el predicado de corrupta. Con tal propósito, se atenderá principalmente al análisis crítico del uso que se le asigna a este término en el ámbito jurídico-penal, tanto en lo que respecta a los tratados internacionales que exigen su criminalización, como en la forma en que ha sido definida por la doctrina ${ }^{16}$.

Una vez que se proponga la delimitación del concepto, a través del examen de sus atributos o elementos esenciales, se ofrecerán criterios que permitan definir aquellas conductas delictivas que debieran ser entendidas como "actos de corrupción". De esta manera se pretende responder tanto al problema de la connotación como al de la referencia, recientemente planteados.

\section{La corrupción como categoría delictiva en sentido amplio.}

En lo que sigue se analizarán dos opciones de delimitación del concepto abordado, centrándonos exclusivamente, en aquellas propuestas que se centren en el uso que se ha asignado a este término en el ámbito jurídico-penal. Como punto de partida, se examinará, en primer lugar, aquella propuesta interpretativa caracterizada por adherir a un concepto amplio de corrupción que, en definitiva, lo terminaría transformando en una especie de categoría general donde podrían ser incluidos delitos muy diversos, tanto en lo que respecta al objeto de tutela como a las modalidades de ataque respectivos. Estos delitos tendrían en común, por lo general, que consistirían en una infracción de deberes con el propósito de obtener beneficios ilícitos.

Esta tendencia se puede observar en las exigencias provenientes de tratados e instrumentos de organismos internacionales destinados a la lucha contra este fenómeno, los que establecen una serie de conductas que debieran ser prohibidas a través del Derecho penal ${ }^{17}$.

\footnotetext{
de la incertidumbre acerca de los atributos que un objeto debe poseer para pertenecer a la clase de que se trate, es decir, depende de la vaguedad intencional del predicado en cuestión”. Basta señalar, por último, que para el autor citado, la vaguedad no puede ser suprimida, sino que solo puede ser "reducida" por medio de definiciones. Al respecto, GUASTINI, Interpretar y argumentar, cit. nota $n^{\circ} 13$, pp. 69-71.

${ }^{16}$ Es importante clarificar el ámbito al que se circunscribe este trabajo. Como de lo que se trata es de delimitar el concepto de corrupción, se recurrirá al análisis de su uso en el ámbito jurídico. Debido a que en este ámbito la corrupción es un fenómeno que va más allá de problemas locales, se ha optado por indagar su uso en los instrumentos internacionales respectivos. Luego se atenderá a la forma como ha sido utilizado en nuestro país principalmente por la doctrina penal. Por lo mismo, se clarifica que no se pretende ofrecer un análisis acabado de los diversos sistemas regulatorios y su forma de reaccionar frente a la corrupción. Por tanto, se recurrirá al método comparado únicamente para detectar ciertos problemas comunes asociados a la delimitación de este concepto y analizar las propuestas de delimitación que se ofrecen, solo en la medida que sea necesario para los propósitos del artículo.

${ }^{17}$ En relación a la "preocupación internacional" por el fenómeno ver, DE LA CUESTA ARZAMENDI, "Iniciativas Internacionales", cit. nota $\mathrm{n}^{\circ}$ 5, pp. 11 y ss.; ROSE-ACKERMAN, Susan, Corruption and Government. Causes, Consequences, and Reform, New York: Cambridge University Press, 1999, p. 177.
} 
ARTAZA, Osvaldo. "La utilidad del concepto de corrupción de cara a la delimitación de la conducta típica en el delito de cohecho".

Si se considera, a modo de ejemplo, la Convención Interamericana Contra la Corrupción de 1996, así como la Convención de las Naciones Unidas contra la Corrupción de $2003^{18}$ se podría evidenciar los motivos por los cuales parte de la doctrina adhiere a tal sentido amplio del término ${ }^{19}$. A partir de tales instrumentos se pueden extraer ciertos datos que serán de suma relevancia para la comprensión del fenómeno analizado. Por lo mismo, se analizará brevemente el contenido de éstos, en lo que sea estrictamente necesario para el objeto de estudio.

Así, por ejemplo, si bien es cierto no se ha definido por la Convención Interamericana lo que se entenderá por corrupción, se identifican las clases de comportamientos que deben ser catalogados como "actos de corrupción". En este sentido, tal instrumento en su artículo VI.1 define las conductas a los que será aplicable la Convención:

a) El requerimiento o la aceptación, directa o indirectamente, por un funcionario público o una persona que ejerza funciones públicas, de cualquier objeto de valor pecuniario u otros beneficios como dádivas, favores, promesas o ventajas para sí mismo o para otra persona o entidad a cambio de la realización u omisión de cualquier acto en el ejercicio de sus funciones públicas;

b) El ofrecimiento o el otorgamiento, directa o indirectamente, a un funcionario público o a una persona que ejerza funciones públicas, de cualquier objeto de valor pecuniario $\mathrm{u}$ otros beneficios como dádivas, favores, promesas o ventajas para ese funcionario público o para otra persona o entidad a cambio de la realización u omisión de cualquier acto en el ejercicio de sus funciones públicas;

c) La realización por parte de un funcionario público o una persona que ejerza funciones públicas de cualquier acto u omisión en el ejercicio de sus funciones, con el fin de obtener ilícitamente beneficios para sí mismo o para un tercero;

d) El aprovechamiento doloso u ocultación de bienes provenientes de cualesquiera de los actos a los que se refiere el presente artículo; y

e) La participación como autor, co-autor, instigador, cómplice, encubridor o en cualquier otra forma en la comisión, tentativa de comisión, asociación o confabulación para la comisión de cualquiera de los actos a los que se refiere el presente artículo.

Por su parte, la Convención de las Naciones Unidas contra la Corrupción, en su Capítulo III, titulado "Penalización y aplicación de la ley", exige o recomienda, en su caso, a los

\footnotetext{
${ }^{18}$ En relación a este instrumento ver, recientemente, ROSE, Cecily, International Anti-Corruption Norms. Their creation and influence on domestic legal systems, Oxford: Oxford University Press, 2015, pp. 99 y ss.

${ }^{19}$ En lo que sigue nos remitimos a RODRÍGUEZ COLLAO, José Luis; OSSANDÓN WIDOW, Magdalena, Delitos contra la función pública, Santiago: Editorial Jurídica de Chile, $2^{\mathrm{a}}$ ed., 2008, pp. 77 y ss. prohibir grupos de acciones que pueden afectar bienes jurídicos relacionados con el correcto desarrollo de la función pública, destacando aquellas conductas que afectarían la probidad de la misma y cierta gama de actuaciones que pueden poner en entre dicho su dimensión patrimonial. Por su parte, también se incorporan una serie de exigencias vinculadas a evitar los efectos nocivos para el orden socioeconómico que pueden derivar de la corrupción, así como aquellas conductas que afectarían la correcta Administración de justicia. Desde esta perspectiva, entonces, se evidencia que el fenómeno en cuestión puede afectar bienes jurídicos de naturaleza muy diversa. Al menos lo anterior es evidente si se compara, por ejemplo, la afectación a la probidad que debe regir la función pública y bienes jurídicos vinculados al orden socioeconómico, como el de la libre competencia.
} 
Polít. crim. Vol. 11, No 21 (Julio 2016), Art. 11, pp. 307-339.

[http://www.politicacriminal.cl/Vol_11/n_21/Vol11N21A11.pdf]

Estados Parte la penalización de una serie de conductas, entre las que destacan: a) el soborno de funcionarios públicos nacionales; b) soborno de funcionarios públicos extranjeros y de funcionarios de organizaciones internacionales; c) la malversación o peculado, la apropiación indebida $u$ otras formas de desviación de bienes por un funcionario público; d) el tráfico de influencias; e) el abuso de funciones; f) el enriquecimiento ilícito; g) el soborno en el sector privado y; f) la malversación o peculado de bienes en el sector privado.

En este orden de cosas llama la atención, inmediatamente, que lo que tendrían en común la mayoría de tales conductas es que, con independencia de los bienes jurídicos que podrían verse afectados, todas ellas serían casos de infracción de deberes funcionariales con el objeto de obtener ventajas indebidas para sí o para terceros ${ }^{20}$.

Es decir, cuando se habla de corrupción se estaría haciendo alusión a un concepto centrado en la infracción de tales deberes (por lo general asociados a la función pública) con el propósito de beneficiar indebidamente a quien infringe tal deber (por lo general decisorio) o a un tercero. Esto es evidente si se considera la figura residual contenida en la Convención Interamericana, de acuerdo con la cual sería un acto de corrupción "la realización por parte de un funcionario público o una persona que ejerza funciones públicas de cualquier acto u omisión en el ejercicio de sus funciones, con el fin de obtener ilícitamente beneficios para sí mismo o para un tercero ${ }^{21}$ ".

Nuestra doctrina reciente también ha asociado la corrupción a las diversas formas como los funcionarios públicos (en un sentido muy amplio) transgredirían, principalmente con fines económicos, las labores propias de su cargo ${ }^{22}$. Por lo mismo, se suelen incluir dentro de tal

\footnotetext{
${ }^{20}$ Lo anterior puede ser puesto en duda en algunos casos, como el del "enriquecimiento ilícito" (Art. 20), o en forma más evidente la penalización del "blanqueo del producto del delito" (art. 23) o del "encubrimiento" (art. 24) o, por último la "obstrucción a la justicia" (art. 25). Con todo, se trata de casos en que no se sanciona directamente los "actos de corrupción" sino que, por lo general, o conductas indiciarias (como el enriquecimiento ilícito) o conductas que pueden facilitar su comisión o impunidad (como el resto de los casos).

${ }^{21}$ Art. VI, 1, c.

${ }^{22}$ Así, por ejemplo, RODRÍGUEZ COLLAO/OSSANDÓN WIDOW, Delitos contra la función pública, cit. nota $\mathrm{n}^{\circ} 19$, p. 89, aunque poniendo énfasis en el elemento de desviación del interés general o interés de la colectividad. Tales autores asumen sin problema un concepto amplio de corrupción en la medida que permitiría "englobar todas las conductas particulares de corrupción". En forma similar, BALMACEDA/CASTRO, Corrupción y delitos contra la administración pública, cit. nota $\mathrm{n}^{\circ} 5$, p. 24 , de acuerdo a los cuales la corrupción "es la desviación del interés público, que se desarrolla a través del abuso del cargo, con el fin de obtener un beneficio extraposicional en la Administración pública". La excepción viene dada por Etcheberry, que asimila expresamente el término corrupción al tipo penal de cohecho. Al respecto, ETCHEBERRY, Alfredo, Derecho Penal Parte Especial, Tomo IV, Santiago: Editorial Jurídica de Chile, $3^{\text {a }}$ ed., 2010, p. 252. En la dogmática comparada se ha criticado definiciones similares a las citadas. Así por ejemplo, Kindhäuser sostiene que tales definiciones están orientadas al autor, resultando demasiado amplias para abarcar lo "específico de la corrupción penalmente relevante". Es importante destacar que el autor citado aborda este problema desde la definición de la corrupción como modalidad de ataque general a diversos bienes jurídicos y, en ningún caso, limitando su alcance a la corrupción en el sector público. Para graficar lo amplio que resulta tal definición constata que efectivamente una gran variedad de conductas delictivas debieran ser entendidas como actos de corrupción, como por ejemplo, ciertas defraudaciones en la medida que se infringen deberes con la motivación ya descrita. Incluso el mero incumplimiento de contratos
} 
ARTAZA, Osvaldo. "La utilidad del concepto de corrupción de cara a la delimitación de la conducta típica en el delito de cohecho".

categoría, conductas delictivas muy diversas. Desde esta perspectiva, se podrían incluir en tal modalidad todos los delitos que han sido clasificados por la doctrina penal como delitos cometidos por funcionarios públicos en el desempeño de sus cargos y que afecten la probidad administrativa, o que consistan en una "falta de probidad" 23 .

La utilidad del concepto de corrupción radicaría en servir como una categoría que incluiría varias modalidades de ataque. Éstas tendrían en común la contravención a deberes de fidelidad debido a la motivación económica ya descrita. Por tanto, podrían ser consideradas como conductas desleales en el marco de una serie de operaciones y negocios efectuados, principalmente, con el sector público ${ }^{24}$.

Sería desleal, por ejemplo, el funcionario que falta a sus deberes de fidelidad para con la Administración y abusa de su poder decisorio para enriquecerse a costa del incumplimiento de su función. Pero también sería desleal y, en este sentido, corrupto, el particular que obtiene un negocio o contraprestación de la Administración pagando en forma indebida, dejando fuera a competidores leales. Por lo mismo, se entiende que tal tendencia considere que el núcleo del concepto esté dado por la infracción de deberes de confianza, o incluso deberes funcionariales, con el objeto de obtener beneficios ilícitos ${ }^{25}$.

Con todo, se puede rescatar de tal aproximación, que reflejaría en forma correcta que sería la corrupción la que afecta o pone en peligro intereses dignos de protección, clarificando así

podría ser catalogado como corrupción atendiendo al alcance asociado a la postura criticada, lo que demostraría la ineficacia de concepto. Véase KINDHÄUSER, "Presupuestos", cit. nota nº 9, p. 5.

${ }^{23}$ GARRIDO MONTT, Mario, Derecho Penal Parte Especial, $4^{\mathrm{a}}$ ed., Santiago: Editorial Jurídica de Chile, 2010, tomo III, pp. 442, donde incluye algunas figuras que considera especialmente relevantes como la malversación de caudales públicos, el cohecho y los fraudes. POLITOFF, Sergio; MATUS, Jean Pierre; RAMÍREZ, María Cecilia, Lecciones de derecho penal chileno, Santiago: Editorial Jurídica de Chile, $2^{\mathrm{a}}$ ed., 2004, pp. 490 y ss., incluyen en tal categoría los delitos de malversación, fraude al fisco, negociación incompatible, uso de información privilegiada y cohecho.

${ }^{24}$ En el ámbito comparado relaciona la corrupción con la deslealtad, por ejemplo, GREEN, Stuart, Mentir; hacer trampas y apropiarse de lo ajeno. Una teoría moral de los delitos de cuello blanco, Trad. AGUSTINA SANLLEHÍ, José Ramón; AMORÓS BAS, Miriam; ORTIZ DE URBINA GIMENO, Iñigo; Madrid, Barcelona, Buenos Aires, Sao Paulo: Marcial Pons, 2013, p. 257. Si bien el autor efectúa tales reflexiones a propósito del delito de cohecho serían plenamente aplicables al término "corrupción" en base a dos razones. En primer lugar, es el mismo autor el que asume que la ambigüedad moral del cohecho viene dada porque aquello "que distingue un soborno de un regalo legítimo es un elemento mental de intención muy difícil de probar (o, de modo aún más obscuro, un elemento de "corrupción»)". Pero en segundo lugar, como se defenderá acá, la corrupción puede ser entendida como la forma de agresión propia del delito de cohecho. Una referencia expresa a la deslealtad para entender la corrupción puede verse en JIMÉNEZ VILLAREJO, Carlos, "Corrupción y sistema político", en: ARROYO ZAPATERO, Luis; NIETO MARTÍN, Adán (Coords.), Fraude y Corrupción en el Derecho penal económico europeo. Eurodelitos de Corrupción y Fraude, Cuenca: Ediciones de la Universidad de Castilla-La Mancha, 2006, p. 395. Desde la perspectiva de los "deberes fiduciarios" véase, CLARK, Kathleen, "Do we have enough ethics in government yet?: An answer from fiduciary theory", University of Illinois Law Review, 57 (1996,) pp. 73 y ss.

${ }^{25}$ Desde una perspectiva conceptual, ARGANDOÑA, Antonio, "La corrupción y las empresas", Occasional Paper IESE Business School-Universidad de Navarra, OP-07/21 (2007), p. 2, disponible en web: http://www.iese.edu/research/pdfs/OP-07-21.pdf [visitado el 28.12.2015] define la corrupción como "el abuso de una posición de confianza para la obtención de un beneficio deshonesto". Como se verá más adelante, este punto de partida ha sido muy criticado debido a su amplitud, y de acuerdo a lo señalado entre nosotros se encontraría ya superado. Al respecto, véase RODRÍGUEZ COLLAO, "Delimitación”, cit. nota n 3, p. 345. 
Polít. crim. Vol. 11, No 21 (Julio 2016), Art. 11, pp. 307-339.

[http://www.politicacriminal.cl/Vol_11/n_21/Vol11N21A11.pdf]

que de lo que se trataría es de una clase de conducta o comportamiento potencialmente lesivo. En palabras de Kindhäuser, la corrupción puede ser comprendida en mejor forma si se tiene como una forma de agresión específica, que debe ser criminalizada cuando pueda afectar en forma grave intereses de especial relevancia ${ }^{26}$.

Sin embargo, y como se demostrará a continuación, el concepto amplio de corrupción no ofrecería una estructura unívoca que lo identifique y diferencie como forma de agresión. Lo que tales instrumentos definen como actos de corrupción incluyen, a su vez, diferencias importantes que impiden categorizarla como una forma de agresión específica.

Por tanto, si bien dicha propuesta es coherente con un uso amplio del término que no puede ser negado, solo presentaría como mérito reflejar un grupo de delitos que tendrían en común el ser cometidos por sujetos en quienes recaen deberes de representación y que pueden infringirlos debido a su codicia o al propósito de beneficiar a terceros, comportándose así en forma desleal con su representado. Es decir, coloca el acento en propiedades del sujeto corrupto más que en la modalidad de su conducta y su delimitación.

Tal extensión asignada al término no refleja que la infracción de deberes decisorios para la obtención de beneficios indebidos puede ser expresada, a través de formas de comportamiento muy diversas. Tanto el funcionario que solicita ventajas indebidas con el objeto de cumplir o infringir sus deberes, como en los casos en que distrae fondos que debe aplicar para fines propios del sector público, o cuando defrauda al fisco produciendo una pérdida patrimonial, infringe deberes funcionariales de la mano de la motivación ya señalada. Con todo, no hay ningún problema en reconocer que las conductas delictivas en tales casos son completamente diversas. Aquellos delitos que debieran ser incluidos en tal categoría, de acuerdo al alcance amplio propuesto por este sector, como el fraude al fisco, la malversación de caudales públicos o el cohecho, en sus diversas manifestaciones, responden a formas de agresión que no podrían ser asimiladas ${ }^{27}$.

En este sentido, el concepto de corrupción sería completamente innecesario o prescindible para la interpretación de las respectivas conductas típicas (es decir, no podría cumplir un papel útil para fines de delimitación de éstas).

\footnotetext{
${ }^{26} \mathrm{Al}$ respecto, KINDHÄUSER, "Presupuestos”, cit. nota $\mathrm{n}^{\circ}$ 9, p. 2, de acuerdo con el cual corrupción “es... una determinada forma de agresión con la que se puede vulnerar los más distintos intereses penalmente protegidos".

${ }^{27}$ Así, por ejemplo, en relación a la conducta típica en el delito de malversación y sus diversas modalidades, RODRÍGUEZ COLLAO/OSSANDÓN WIDOW, Delitos contra la función pública, cit. nota ${ }^{\circ} 19$, pp. 384 y ss., distinguen entre malversación por apropiación o peculado (art. 233, modalidad dolosa, y art. 234, supuesto culposo); malversación por distracción o desfalco (art. 235); malversación por aplicación pública diferente (art. 236) y negativa a un pago o entrega (art. 237). Posteriormente, los mismos autores destacan que el delito de fraude al fisco contemplado en el artículo 239 del Código Penal consiste en "defraudar o consentir en que se defraude", siendo asimilado a una forma de estafa o defraudación.
} 
ARTAZA, Osvaldo. "La utilidad del concepto de corrupción de cara a la delimitación de la conducta típica en el delito de cohecho".

\section{Concepto restringido de corrupción como forma de agresión específica.}

Como señala Kindhäuser, es necesario delimitar aquello que sea específico de la corrupción como forma de agresión ${ }^{28}$. El mismo autor, en un intento por demarcar este concepto en atención a tal función, sostiene que el camino correcto para tal tarea pasa por atender a la estructura relacional de la misma.

No cualquier infracción de deberes para la obtención de ventajas ilícitas es corrupción, ya que ésta solo se presentaría en un determinado contexto relacional. Un aspecto de esta estructura relacional es bastante evidente: todas las conductas en cuestión tienen en común el hecho de que se infringen ciertos deberes. En nuestro medio, por lo general, esto ha estado asociado a la infracción de deberes del cargo en los delitos cometidos por funcionarios públicos. En esta estructura, que hasta el momento se compone de dos sujetos, se abusa de poderes decisorios en forma contraria a los intereses que debieran ser considerados como primordiales (los del representado), debido a una priorización no autorizada de intereses secundarios (los del representante actuando como privado ${ }^{29}$.

Sin embargo, este concepto puede ser mayormente delimitado. Para tales efectos, debemos abordar en forma más detallada la estructura relacional del mismo. Para que estemos frente a un acto de corrupción no basta con que el abuso del poder decisorio se efectúe a través de la priorización de un interés secundario por sobre el interés primario esperado. Se requiere, además, que tal abuso esté en directa relación con la generación de una ventaja ilícita a un externo a esta relación bilateral original. Es decir, a un tercero interesado que quedaría en mejor posición, en forma no autorizada, que el resto de los terceros debido al beneficio que otorga a quien abusa de tal poder.

En la corrupción, la razón por la cual se desnaturaliza esta pauta ideal (el interés del representado) necesariamente debe estar vinculada a un tercero que interviene o potencialmente puede intervenir en tal proceso de degeneración. Por ejemplo, como se verá más adelante en relación al delito de cohecho, tal vinculación se concretaría a través del ofrecimiento o la aceptación de entregar una ventaja indebida. Por tal motivo se explicaría que en ocasiones se entienda este delito como una especie de compraventa de la función pública ${ }^{30}$, ya que en este tipo penal no solo sería relevante la relación entre el

\footnotetext{
${ }^{28}$ KINDHÄUSER, "Presupuestos", cit. nota n 9, p. 5.

${ }^{29}$ Esta sería la visión tradicional de corrupción que derivaría de los instrumentos internacionales ya mencionados. En un sentido similar LOMBANA VILLALBA, Jaime, "La tipificación”, cit. nota n 10, p. 14. Dicho autor señala: “Así, por ejemplo, es usual sostener que lo característico de la corrupción es el desvío de los intereses generales hacia intereses privados en forma incompatible con ciertas normas jurídicas e incluso éticas. Lo propio de la corrupción sería entonces esta confusión de esferas de lo público y lo privado así como "la desviación del interés general hacia el particular".

30 Así, por ejemplo, NIETO MARTÍN, Adán, "La corrupción en las transacciones comerciales internacionales", en: NIETO MARTÍN, Adán (Coord.), Estudios de Derecho Penal, Universidad Castilla-La Mancha, 2004, pp. 75-76, en lo que respecta a la definición del delito de cohecho entendido como un delito de corrupción a funcionarios públicos.
} 
Polít. crim. Vol. 11, No 21 (Julio 2016), Art. 11, pp. 307-339.

[http://www.politicacriminal.cl/Vol_11/n_21/Vol11N21A11.pdf]

representante y su representado, sino que también entre el primero y un tercero que ofrece tal ventaja o que acepta entregarla ${ }^{31}$.

Lo anterior demuestra que los actos de corrupción, si bien pueden ser categorizados como actos de deslealtad para con otro, deben ser entendidos, a su vez, como un subconjunto más limitado que el primero, debido a que exigen que se desarrollen a propósito de su representación frente a terceros. En este orden de cosas, Kindhäuser señala que la doctrina alemana mayoritaria considera que lo esencial de la corrupción es el "intercambio irregular de ventajas" o el "acuerdo delictivo" "32. La infracción del deber consistiría, de acuerdo a tal posición dominante, en una prestación debido al "otorgamiento de una ventaja". Desde la perspectiva relacional que interesa, queda claro que el acto de corrupción requiere tanto de quien otorga una ventaja ilícita, como de aquel que actúa en razón de la misma.

Continuando con la descripción de la propuesta de este autor, debemos considerar una serie de aspectos constitutivos de la corrupción o elementos esenciales. En primer lugar, la recompensa o el otorgamiento de la ventaja debe estar referida a una especial posición de deber a favor de otro. En segundo lugar, y como una consecuencia del primer elemento, tal ventaja no debe ser útil para la actuación funcionarial del "encargado"33. Es decir, es esencial que la ventaja vaya en contra del interés en el correcto ejercicio de la actuación funcionarial, lo que sucede cuando ésta sea incompatible con los intereses declarados por el representado.

Hasta ahora lo que se ha hecho es simplemente ahondar en la estructura relacional del concepto con fines meramente analíticos. Como se pretende demostrar a continuación, este

\footnotetext{
${ }^{31}$ Posición que, como es obvio al menos en el delito de cohecho, puede ser adoptada indistintamente tanto por el privado como por el funcionario público, como se desprende de los tipos penales que se conocen respectivamente como cohecho activo y cohecho pasivo.

${ }^{32}$ KINDHÄUSER, "Presupuestos", cit. nota $n^{\circ}$ 9, p. 5. Posteriormente, en p. 6 propone definir corrupción como "la vinculación contraria a intereses de una ventaja con el ejercicio de un poder de decisión transferido". Tal concepto permitiría corregir el exceso que derivaría de la postura dominante en Alemania que sostendría que el elemento esencial de la corrupción sería el "intercambio delictivo" o un "intercambio irregular de ventajas". Esta aproximación sería correcta en la medida que se centra en el aspecto relacional, pero sería inútil como criterio delimitador de la corrupción como modalidad de ataque. Adhiere expresamente a tal propuesta conceptual, MAÑALICH, Juan Pablo, "La negociación incompatible como delito de corrupción: estructura típica y criterios de imputación”, Revista de Estudios de la Justicia, No23 (2015).

${ }^{33}$ KINDHÄUSER, "Presupuestos", cit. nota n ${ }^{\circ}$ 9, p. 7. De acuerdo a este autor los elementos de la corrupción serían tres. En primer lugar, requeriría una relación trilateral. A una persona se le debe haber confiado la tarea de actuar en interés de un tercero, ahora, como señala el autor, para que valga la pena la ventaja ofrecida, debe por lo general ser una persona que pueda tomar decisiones de cierto peso, como por ejemplo, actuaciones jurídicamente relevantes. En ese orden de cosas, también concurre quien pueda otorgar la ventaja, que no necesariamente es el mismo que se vería afectado por la decisión, ya que también podría ser un tercero ajeno por completo a la relación. En segundo lugar, la ventaja no necesariamente se debe referir a un beneficio económico o financiero, ya que todo lo que pueda motivar a un ser humano puede entrar en consideración como ventaja. Obviamente este elemento de la corrupción puede ser limitado por el legislador, como en el caso del tipo de cohecho en Chile, donde el beneficio debe ser necesariamente económico, sin perjuicio de lo cuestionable que resulte tal decisión tomando en cuenta que otros factores pueden ser igualmente relevantes para motivar al encargado. En tercer lugar, y de acuerdo a esta postura, para que exista corrupción el otorgamiento de la ventaja debe estar referida a una posición de deber del encargado, y que la relación entre la posición de deber y la ventaja indebida lleve al encargado a una incompatibilidad de intereses.
} 
ARTAZA, Osvaldo. "La utilidad del concepto de corrupción de cara a la delimitación de la conducta típica en el delito de cohecho".

concepto restringido sería sumamente útil para la concreción del comportamiento prohibido en los actos de corrupción.

En lo que sigue se analizará la utilidad de este concepto a propósito de la interpretación del delito de cohecho, ya que este tipo penal respondería necesariamente a la estructura relacional trilateral ya descrita. Como se intentará de demostrar, ciertos problemas relativos a la delimitación de la conducta típica podrían ser abordados satisfactoriamente con la ayuda del concepto de corrupción.

\section{Primera aproximación a la utilidad del concepto de corrupción para la delimitación de la conducta típica en el delito de cohecho ${ }^{34}$.}

Oliver ha definido el delito de cohecho como la "conducta activa o pasiva de un particular destinada a dar a un funcionario público una retribución no debida en el ejercicio del cargo de éste" ${ }^{35}$. Tal definición refleja que tanto el funcionario como el particular pueden ser tenidos como sujeto activo de este delito, ya sea a través de una conducta activa (solicitar u ofrecer el beneficio económico, respectivamente), como a través de una conducta pasiva (aceptar el beneficio o acceder a la solicitud) ${ }^{36}$. Como señalé anteriormente, en el caso de este tipo penal, las formas de agresión al bien jurídico contemplan ciertas características que permiten predicar su especialidad como conducta delictiva.

A diferencia de otros delitos que consisten en la infracción de deberes propios del cargo motivados por la consecución de ventajas indebidas, la estructura del cohecho no es solo bilateral, sino que es necesariamente trilateral ${ }^{37}$. Un buen ejemplo para dar cuenta de tal

\footnotetext{
${ }^{34}$ Se debe clarificar que en razón de la extensión del trabajo, no es posible abordar aspectos fundamentales del tipo penal, como por ejemplo, el papel que juega el "tráfico de influencias" en su estructura, sin perjuicio de que tales aspectos puedan ser abordados en el futuro.

${ }^{35}$ OLIVER, Guillermo, “Aproximación al delito de cohecho”, Revista de Estudios de la Justicia, N5 (2004), p. 87. Por su parte, otro sector doctrinario al definir cohecho realiza una serie de distinciones, entre cohecho pasivo y activo, y entre cohecho propio e impropio. "El cohecho propiamente tal consiste en aceptar dádiva para la ejecución de actos funcionarios que deberían realizarse gratuitamente, y por eso a tal conducta se le llama cohecho propio. En nuestra ley se contempla además a la aceptación de dádiva o promesa para la realización de delitos funcionarios, conducta que sólo por analogía puede llamarse cohecho, en razón de lo cual es denominado cohecho impropio". Así, ETCHEBERRY, Derecho Penal Parte Especial, cit. nota ${ }^{\circ} 22$, p. 253. En un sentido similar en cuanto a asignarle mayor relevancia a la clasificación de cohecho más que a una definición unitaria, véase, POLITOFF/MATUS/RAMÍREZ, Lecciones de derecho penal chileno, cit. nota $\mathrm{n}^{\circ} 23$, pp. 502 y ss.

${ }^{36}$ Se critica en la actualidad la clasificación usual de la doctrina entre el cohecho activo (cometido por particular) y el cohecho pasivo (cometido por el funcionario), ya que en el primer caso también se sancionaría una conducta pasiva del particular, así como en el segundo una conducta activa del funcionario. Por otro lado, también se pone en duda la necesidad de mantener la clasificación tradicional entre cohecho propio (aquel en que lo que se busca sea la "ejecución u omisión cuando lo que se busque sea la ejecución o la omisión de un acto propio del cargo del empleado público"), e impropio (caracterizado porque lo requerido es la comisión de un delito funcionario). Sobre las críticas a estas clasificaciones, véase OLIVER, “Aproximación”, cit. nota n 35, pp. 88-90.

${ }^{37}$ Por ejemplo, es evidente que tal estructura trilateral no se presenta en todos los delitos que en forma habitual son definidos como actos de corrupción. Solo a modo de ejemplo, ya que lo que interesará a continuación es explorar el rendimiento práctico de este concepto, la malversación de caudales públicos solo presentaría una estructura bilateral, ya que para su configuración se requiere de la presencia del representante
} 
Polít. crim. Vol. 11, No 21 (Julio 2016), Art. 11, pp. 307-339.

[http://www.politicacriminal.cl/Vol_11/n_21/Vol11N21A11.pdf]

realidad está dada por la definición de cohecho propuesta por Green ${ }^{38}$. De acuerdo a este autor, el delito de cohecho podría expresarse de la siguiente manera: " $X$ (quien recibe el soborno) es sobornado por $Y$ (quien lo ofrece), si y sólo si: 1) $X$ acepta, o acuerda aceptar, algo de valor proveniente de $Y$; 2) a cambio de que $\mathrm{X}$ actúe o acuerde actuar a favor de cierto interés de $Y$, y 3 ) infringiendo un deber de lealtad propio de $X$, que se desprende de su función pública, posición o trabajo".

Esta definición, si bien no responde a todas las modalidades que presenta el cohecho en nuestra legislación, ya que no incluiría los casos en que $\mathrm{X}$ es quien solicita el beneficio económico para los efectos descritos en la definición, sirve para constatar la naturaleza trilateral en lo que se refiere a las relaciones necesarias para su configuración. Una primera aproximación a la definición podría dar a entender que se trataría exclusivamente de una estructura bilateral, ya que incluso los sujetos mencionados parecen ser solo dos, $\mathrm{X} \mathrm{e} \mathrm{Y}^{39}$. Sin embargo, tal punto de partida olvida que, por definición, uno de los integrantes de tal relación, $X$, es relevante exclusivamente en su calidad de representante de intereses ajenos, lo que pasa a ser central dentro de esta estructura.

Ahora, si se parte de la base que el delito de cohecho presenta la estructura relacional descrita dada por su naturaleza de un "acto de corrupción", se puede delimitar su contenido atendiendo esta misma estructura, especialmente a sus niveles, elementos y características.

Así, y solo a modo de ejemplo, un primer nivel estaría constituido por la relación propia del representante y el representado (en el ámbito de la corrupción en el sector público, entre el funcionario y el Estado al que representa). En este primer nivel se presentarían los siguientes problemas:

y del representado. El malversador infringe los deberes que tiene para con el mandatario relativos a la aplicación de los recursos (en términos amplios y simplificando el problema). Esta relación bilateral se presentaría incluso cuando hay un particular involucrado, como en los casos en que los efectos o caudales sean de particulares. Y esto es así porque el particular realmente no participa en forma relevante o no interviene en la modalidad de ataque del bien jurídico, donde solo es relevante que el encargado infrinja las expectativas propias de su cargo relativas a la custodia o administración de tales recursos.

${ }^{38}$ GREEN, Mentir; hacer trampas y apropiarse de lo ajeno, cit. nota ${ }^{\circ} 24$, p. 258. Si bien es cierto el autor presenta esta definición como propuesta de estructura común del “bribery” en el ámbito angloamericano, resulta plenamente aplicable a los fines de este trabajo, en la medida que nos centraremos en las relaciones propia de la corrupción, las que justamente se dan en el marco de lo que se conoce como soborno (y sus diversas modalidades).

${ }^{39}$ Se debe aclarar que la afirmación de la trilateralidad del cohecho no se relaciona con la discusión habitual de la dogmática penal relativa a la naturaleza bilateral o unilateral de este delito. Al respecto RODRÍGUEZ COLLAO/OSSANDÓN WIDOW, Delitos contra la función pública, cit. nota $\mathrm{n}^{\circ}$ 19, pp. 327-328; en igual término OLIVER, “Aproximación”, cit. nota ${ }^{\circ}$ 35, pp. 91-92, que sostiene que a partir de la promulgación de la Ley 19.645 ya no se puede defender una estructura bilateral de tal delito debido a que "para apreciar un delito de cohecho de funcionario dejó de ser necesario que existiera acuerdo entre éste y un particular". Con lo anterior se expresa que la conducta típica se satisface con el mero ofrecimiento sin necesidad de aceptación ya sea por parte de uno u otro. Con todo, lo anterior no permite sostener que la naturaleza del delito sea unilateral, ya que lo que no se pone en duda es que debe existir un oferente y un potencial aceptante. Que el legislador, por técnica legislativa, opte por sancionar desde que uno de tales intervinientes actúa no impide asumir la naturaleza relacional ya formulada. 
ARTAZA, Osvaldo. "La utilidad del concepto de corrupción de cara a la delimitación de la conducta típica en el delito de cohecho".

a) La concreción del sujeto que puede figurar como representante, así como la necesaria vinculación que debe darse entre la toma de decisión y los deberes funcionariales. La pregunta de "quién puede ser sobornado" representaría, en parte, este primer problema.

b) La naturaleza o contenido de la decisión adoptada por el funcionario y su relación con la ventaja obtenida $u$ ofrecida.

En un segundo nivel relacional, dado por la relación entre el representante y el tercero con el cual se relaciona en representación de otro, encontramos problemas diversos. Así, por ejemplo:

a) Las características de la conducta del tercero para ser considerada como idónea para corromper, es decir, para servir de razón para que el representante priorice intereses secundarios que sean incompatibles a los de su representado ${ }^{40}$.

b) El estatus que deben presentar ambas partes para que estemos frente a un acto de corrupción, y así diferenciarlo de ciertos casos en que la solicitud efectuada por el representante al tercero deba ser comprendida como un acto de abuso o extorsión.

En lo que sigue se analizarán algunos aspectos centrales del tipo penal que podrían ser estudiados desde la delimitación del concepto de corrupción propuesta ${ }^{41}$. Así, por ejemplo, se abordará en primer lugar, en forma muy sucinta, el problema del bien jurídico protegido por el delito de cohecho, debido a que éste puede delimitarse atendiendo a las razones por las cuales parece necesario dictar normas prohibitivas relativas a los actos de corrupción. Luego, se analizará cómo la estructura de la corrupción permitiría explicar la extensión que se le ha dado en nuestro ordenamiento jurídico al concepto de empleado público. Lo anterior como paso necesario para ahondar en algunos aspectos problemáticos relativos a la conducta típica, donde se pretende demostrar el eventual potencial práctico asociado al concepto estudiado.

\subsection{El bien jurídico protegido en el delito de cohecho.}

En relación con el bien jurídico protegido por este tipo penal, es posible advertir dos tendencias en nuestra doctrina. Por una parte se ha dicho que este tipo penal protege en forma genérica la probidad de la función pública ${ }^{42}$, o que protegería ciertas condiciones

\footnotetext{
${ }^{40}$ Obviamente el problema se refiere a uno de las posibilidades de la corrupción, esto es, cuando es el tercero el que ofrece determinada ventaja al representante con el propósito de influir en su decisión.

${ }^{41}$ Como ya se explicó, no es objeto de este artículo abordar en forma completa el delito en particular. Solamente nos interesa constatar algunos aspectos referidos a su tratamiento por parte de la doctrina nacional, relativos al bien jurídico protegido, sujeto activo y a la conducta típica que podrían ser adecuadamente delimitados recurriendo a la estructura relacional del concepto de corrupción. En ocasiones se recurrirá a la doctrina comparada, pero solo para los casos en que sea necesario debido a que se detecte vías de solución a los problemas de delimitación ya abordados o a la constatación de problemas de delimitación comunes que podrían abordarse también desde el punto de vista propuesto.

${ }^{42}$ Así, en forma expresa GARRIDO MONTT, Derecho Penal, cit. nota n 23, p. 454: "Estas figuras tienden a proteger la probidad de la administración el Estado, que aquellos encargados de la gestión del Estado tengan el comportamiento adecuado al ejercicio de sus respectivos cargos; en síntesis, lo que se aspira es marginar o evitar la corrupción". También, en forma similar, aunque un tanto más amplia, LABATUT GLENA, Gustavo, Derecho Penal, Tomo II, Santiago: Editorial Jurídica de Chile, $7^{\mathrm{a}}$ ed., 1983, p. 90, al sostener que el bien
} 
Polít. crim. Vol. 11, № 21 (Julio 2016), Art. 11, pp. 307-339.

[http://www.politicacriminal.cl/Vol_11/n_21/Vol11N21A11.pdf]

mínimas que incidirían en el buen desempeño de la misma ${ }^{43}$. A esta tendencia se le ha criticado que solo pretendería proteger la corrección de la función estatal, colocando el acento en el mero cumplimiento de deberes por parte del funcionario respectivo. Por lo mismo, parte de nuestra doctrina, por ejemplo, Rodríguez Collao, ha sostenido que tal tendencia no da cuenta de un bien jurídico que sea merecedor de protección penal, en la medida que no debieran criminalizarse meras infracciones a deberes personales si éstos no tienen correlato concreto en "la afectación de los derechos o de las legítimas expectativas de la ciudadanía ${ }^{44,}$.

En ese orden de cosas, ya no parecería suficiente la protección sin más de la función pública si no está conectada con los destinatarios de tal función, es decir, los ciudadanos. Por lo mismo, este autor sostiene que lo que se protege a través de la criminalización de esta conducta es el principio de imparcialidad que debe regir la actividad de la administración en su trato con los destinatarios de tal función ${ }^{45}$. A partir de la consideración del delito de cohecho como un acto de corrupción, se entiende que, a través de éste, no se puedan proteger todas las expectativas relativas al desempeño correcto de la relación entre la administración del Estado y los ciudadanos, sino que solo un margen limitado de ellas.

jurídico protegido por este tipo penal es "el decoro, el prestigio y el correcto funcionamiento de la función pública".

${ }^{43}$ En este sentido, se puede considerar lo dispuesto, entre nosotros, por ETCHEBERRY, Derecho Penal Parte Especial, cit. nota ${ }^{\circ} 22$, p. 203, de acuerdo con el cual el Título V del Libro II del Código penal chileno, con independencia de que pareciera que el legislador habría agrupado una serie de delitos en este Título en razón del sujeto activo y no de un bien jurídico en particular, protegería lo que ha denominado como la "recta administración pública". Para la recta administración pública se deben dar, desde luego, una serie de condiciones, dentro de las que destacarían la de probidad, la confianza que debiera inspirar quienes la desempeñan, su prestigio, etc. Como parece claro, esta primera aproximación sostiene que el delito de cohecho protege, como bien jurídico, alguna de tales condiciones, poniendo el acento, entonces en la corrección de tal función. Para una aproximación la discusión en España, que presenta varias coincidencias con la nuestra ver, DÍAZ Y GARCÍA CONLLEDO, Miguel, "Corrupción y delitos contra la administración pública. Insuficiencias y límites del derecho penal en la lucha contra la corrupción: el ejemplo español", Revista de Derecho, № 7 (2004), pp. 165 y ss.; VALEIJE ÁLVAREZ, Inmaculada, "Consideraciones sobre el bien jurídico protegido en el delito de cohecho", Estudios penales y criminológicos, № 18 (1994-95), pp., 318 y ss., en donde describe la discusión acerca de si se puede decir que este delito protege un solo bien jurídico en sus diversas modalidades o se debe distinguir entre lo que se conoce como cohecho activo y cohecho pasivo.

${ }^{44}$ RODRÍGUEZ COLLAO, José Luis, "La función pública como objeto de tutela penal”, Revista de Derecho Pontificia Universidad Católica de Valparaíso, vol. 1, núm. XXVI (2005), p. 331. Asimismo, OLIVER, “Aproximación", cit. nota ${ }^{\circ} 35$, p. 93. de acuerdo al cual esta posición debiera ser criticada ya que "eleva a la categoría de bien jurídico tutelado en el cohecho del empleado público el deber funcionarial, lo que revela una visión autoritaria que no tiene en cuenta que la existencia de la Administración Pública se explica, únicamente, por el beneficio que su actividad significa para los ciudadanos. Los deberes que emanan de los cargos públicos no se explican por sí solos, sino en cuanto su cumplimiento conduce a la prestación de un servicio para la comunidad." Para una reflexión similar en el ámbito comparado, ver DE LA MATA, Norberto J., “¿Qué interés lesionan las conductas de corrupción?”, Eguzkilore, № 23 (2009), pp. 246 y ss.; EL MISMO, "El bien jurídico protegido en el delito de cohecho. La necesidad de definir el interés merecedor y necesitado de tutela en cada una de las conductas típicas encuadradas en lo que se conoce, demasiado genéricamente, como ámbito de la corrupción”, Revista de Derecho Penal y Criminología, 2a época, N $^{\circ} 17$ (2006), pp. 95 y ss.

${ }^{45}$ RODRÍGUEZ COLLAO, "La función pública”, cit. nota n 44, pp. 330 y ss. 
ARTAZA, Osvaldo. "La utilidad del concepto de corrupción de cara a la delimitación de la conducta típica en el delito de cohecho".

Y esto, porque, si se asume la estructura relacional planteada, resulta evidente que la infidelidad con los deberes del cargo solo adquiere relevancia jurídico penal, de cara al delito de cohecho, en la medida que se entiendan como una forma indebida de representación, o como una forma no autorizada de relación con los ciudadanos de acuerdo a los intereses declarados del representado (Estado).

Esa es la razón por la cual parece razonable adherir a la posición que sostiene que el bien jurídico protegido por este tipo penal es la "imparcialidad" de la función pública. El concepto de imparcialidad delimita el margen de acción del funcionario a su relación con terceros y precisamente da cuenta de un interés declarado por el Estado que, al menos entre nosotros, se enmarca en el principio de igualdad y la prohibición de toda forma de discriminación arbitraria ${ }^{46}$.

Cuando el funcionario público abusa de su poder decisorio en el marco de su relación con terceros, y tergiversa las condiciones de acceso de los ciudadanos a las diversas prestaciones de las que es competente, genera ventajas comparativas indebidas en cierto sector de la población. Afecta así, en forma grave, expectativas normativas de los ciudadanos relativas a las condiciones necesarias para promover su participación en forma igualitaria.

Como se verá más adelante, tal conclusión relativa al bien jurídico protegido por el tipo penal será fundamental para delimitar el margen de conductas que debieran ser consideradas jurídico penalmente relevantes por su idoneidad para la afectación de tales intereses.

\subsection{La categoría de "empleado público" en el delito de cohecho.}

Si se analiza el tipo penal de cohecho a partir del concepto y estructura de la corrupción, se puede comprender mejor la importancia de concretar el sujeto de la relación trilateral que representa intereses ajenos y puede abusar de sus poderes decisorios. Es decir, un paso fundamental para responder al problema de la conducta típica, estaría dado por definir quiénes pueden ser considerados como representantes ${ }^{47}$. Solo así se podrá precisar luego

\footnotetext{
${ }^{46}$ Nuestra Constitución Política de la República en su artículo primero señala que: "Las personas nacen libres e iguales en dignidad y derechos". Por su parte, el artículo 16 del referido cuerpo normativo establece que: "Se prohíbe cualquiera discriminación que no se base en la capacidad o idoneidad personal (...)". Esto no significa que este principio sea el único que rige la relación entre la Administración y los ciudadanos, pero presenta la ventaja de satisfacer la necesaria vinculación de tal interés con las posibilidades de desarrollo de los individuos, y representa un interés de tal relevancia que los ataques que se consideren especialmente intolerables contra las mismas puedan ser objeto de prohibición a través del derecho penal, como exigencia mínima para su criminalización.

${ }^{47}$ Resulta interesante analizar cómo en el ámbito comparado, también ha sido determinar quién es susceptible de ser sobornado. Así, por ejemplo, GREEN, Mentir; hacer trampas y apropiarse de lo ajeno, cit. nota $n^{\circ} 24$, para el caso de Estados Unidos e Inglaterra. El autor analiza como en el ámbito del common law se ha producido la tendencia de aumentar el ámbito de personas "susceptibles de ser sobornadas", principalmente por la ampliación de quienes podían ser considerados como "funcionarios públicos". Ver también, para España, MIR PUIG, Carlos, “Artículos 404-445”, en: MIR PUIG, Santiago; CORCOY, Mirentxu, (Dirs.), Comentarios al Código Penal. Reforma LO 1/2015 y LO 2/2015, Valencia: Tirant Lo Blanch, 2015. p. 1409, quien describe como a partir de las últimas modificaciones del Código penal español (especialmente reforma
} 
Polít. crim. Vol. 11, No 21 (Julio 2016), Art. 11, pp. 307-339.

[http://www.politicacriminal.cl/Vol_11/n_21/Vol11N21A11.pdf]

qué se entiende por abuso de poder decisorio en el marco de su relación con terceros. Tal concepto estará inevitablemente ligado a su poder de representación y a la determinación de cuándo se infringe el mismo.

En nuestro ámbito, tal preocupación ha sido abordada a través de la delimitación del concepto de empleado público, en el marco de los delitos contenidos en el Título IV del Libro II del Código penal. El punto de partida obligatorio para la definición de "empleado público" viene dado por lo dispuesto por el artículo 260 del Código penal ${ }^{48}$.

De acuerdo a Etcheberry lo central de tal concepto sería la constatación de que se desarrolle una "función pública", ya que, como señala este autor, para el derecho penal la "función crea al empleado, y no a la inversa ${ }^{49,}$.

Por lo mismo, si es la función desarrollada la que define quiénes se pueden incluir en tal categoría, para la resolución del problema se debe aclarar qué se entiende por "función pública”. Entre nosotros, Rodríguez Collao y Ossandón Widow consideran que puede ser útil lo consagrado por la Convención Interamericana contra la Corrupción, que la ha definido en su artículo primero como "toda actividad temporal o permanente, remunerada u honoraria, realizada por una persona natural en nombre del Estado o de sus entidades, en cualquiera de los niveles jerárquicos ${ }^{50 \%}$.

de 2010 y de 2015), se amplía este círculo de sujetos incluso a "los jurados, árbitros, peritos, o cualesquiera personas que participen en el ejercicio de la función pública...". La última reforma (2015) incluye a "los mediadores y a los administradores concursales", y esto solo en lo que respecta a los funcionarios "nacionales" y no a los de estados extranjeros o de una organización internacional. Ver, al respecto, JAVATO MARTÍN, Antonio, "El concepto de funcionario y autoridad a efectos penales", Revista Jurídica de Castilla y León, $\mathrm{N}^{\circ} 23$ (2011), pp. 152 y ss.

${ }^{48}$ De acuerdo con el cual, “....se reputa empleado todo el que desempeñe un cargo o función pública, sea en la Administración Central o en instituciones o empresas semifiscales, municipales, autónomas u organismos creados por el Estado o dependientes de él, aunque no sean del nombramiento del Jefe de la República ni reciban sueldos del Estado. No obstará a esta calificación el que el cargo sea de elección popular”. En relación a la historia de este precepto ver ETCHBERRY, Derecho Penal Parte Especial, cit. nota n ${ }^{\circ} 22$, pp. 204-205. Ver también RODRÍGUEZ COLLAO/OSSANDÓN WIDOW, Delitos contra la función pública, cit. nota ${ }^{\circ}$ 19, pp. 121 y ss. Al respecto, OSSANDÓN WIDOW, Magdalena, "Sobre la calidad de empleado público en los delitos de funcionario", Concepto de empleado público y problemas de comunicabilidad, Santiago: Abeledo Perrot, Thomson Reuters, Universidad de Los Andes, 2012, p.52, señala que analizar el alcance de dicha disposición, es necesario tener en cuenta que el concepto de funcionario público puede analizarse desde diversos criterios. Entre ellos se encuentra un criterio formal objetivo, formal subjetivo, y teleológico o funcional. A juicio de la autora nuestro Código Penal recogería un criterio teleológico funcional. También a favor de la tesis funcionalista, POLITOFF/MATUS/RAMÍREZ, Lecciones de derecho penal chileno, cit. nota $\mathrm{n}^{\circ} 23$, p. 487. Nuestra Corte Suprema a su vez se ha pronunciado sobre el alcance del concepto de funcionario público, Rol 2321-2007, de 19 de Mayo de 2008, considerando cuadragésimo sexto: "en efecto, al ser posibles de cometer delitos ministeriales no sólo las personas que ocupan un cargo público, sea de planta o a contrata, sino también aquellas que adscriben a una "función pública", la condición de potenciales sujetos activos de esta categoría de ilícitos se ha ensanchado ostensiblemente, para encerrar en la noción correspondiente a todos los que cumplen tareas en el sector público- y no tan sólo en la Administración del Estado- con el solo requisito de prestar servicios en un órgano del Estado, aun ajeno al Poder Ejecutivo".

${ }^{49}$ ETCHEBERRY, Derecho Penal Parte Especial, cit. nota n ${ }^{\circ} 22$, p. 205.

${ }^{50}$ RODRÍGUEZ COLLAO/OSSANDÓN WIDOW, Delitos contra la función pública, cit. nota n ${ }^{\circ}$, p. 125. 
ARTAZA, Osvaldo. "La utilidad del concepto de corrupción de cara a la delimitación de la conducta típica en el delito de cohecho".

En forma similar nuestra Corte Suprema ha sostenido que la función pública debe ser entendida como "función el Estado", y que para determinar quién puede ejercer tales funciones es irrelevante que se ocupe un cargo público, debiendo incluirse a todo aquel que "cumple tareas en el sector público 51 ". Simplificando el problema, se puede decir que tanto doctrina como jurisprudencia asumen que lo relevante es que el sujeto esté habilitado para actuar en nombre del Estado ${ }^{52}$.

Por tanto, no se ha puesto en duda que para efectos de este tipo penal el sujeto no requiere ostentar el cargo de funcionario público, sino que desempeñar una función pública. En el fondo, lo relevante es que el sujeto deba actuar representando intereses ajenos, que en este caso corresponden a la Administración pública.

A partir de tal constatación se podría abordar en mejor forma algunos problemas que se han presentado de cara a la delimitación de la conducta típica. Estos problemas están vinculados a un segundo aspecto del nivel relacional compuesto por el representante y el representado, y que dice relación con la concreción del margen de comportamiento que puede ser entendido como un abuso del poder decisorio aparejado a su posición de representante.

Como se verá a continuación, lo anterior es fundamental para la interpretación del delito de cohecho, en la medida que las disposiciones jurídicas pertinentes exigen que la actuación del funcionario esté conectada en forma específica al desempeño de su cargo. En forma breve: que abuse de su poder decisorio mediante la solicitud o su aceptación de un beneficio indebido para ejecutar o por haber ejecutado un acto propio de su cargo, para omitir o infringir sus deberes o por haberlo hecho, o para la comisión de determinados delitos.

\subsection{La conducta típica del delito de cohecho.}

\subsubsection{Exigencias relativas a la actuación de un representante.}

En relación a la conducta típica, se deben distinguir las respectivas modalidades que presenta este delito. La figura básica del delito de cohecho cometido por funcionario público está regulada por el art. 248 del Código penal, que sanciona al empleado público que solicita o acepta "recibir mayores derechos que los que le están señalados por razón de su cargo $^{53}$, o un beneficio económico ${ }^{54}$ para sí o un tercero para ejecutar o por haber ejecutado un acto propio de su cargo, en razón del cual no le están señalados derechos”.

\footnotetext{
${ }^{51}$ Sentencia Corte Suprema, Rol No 2321-2007, considerandos cuadragésimo sexto y séptimo.

${ }^{52}$ Sobre las nociones de funcionario público y función pública, véase RODRÍGUEZ COLLAO/OSSANDÓN WIDOW, Delitos contra la función pública, cit. nota $\mathrm{n}^{\circ}$ 19, pp. 124 y ss. En relación al "concepto funcional de empleado público" véase POLITOFF/MATUS/RAMÍREZ, Lecciones de derecho penal, cit. nota $\mathrm{n}^{\circ} 23$, p. 487.

${ }^{53} \mathrm{Al}$ respecto, OLIVER, “Aproximación”, cit. nota $\mathrm{n}^{\circ} 35$, p. 97, donde el autor indica que esta situación podría darse cuando el funcionario no tiene derecho a cobrar monto alguno debido a que la prestación respectiva no tiene asociado algún costo o porque en razón a circunstancias personales del beneficiado no pueda cobrar en el caso en particular.

${ }^{54}$ No parece discutible que nuestro legislador haya restringido el campo de aplicación de este tipo penal a los casos en que la ventaja recibida por parte del funcionario sea de contenido patrimonial, lo que se desprendería
} 
Polít. crim. Vol. 11, No 21 (Julio 2016), Art. 11, pp. 307-339.

[http://www.politicacriminal.cl/Vol_11/n_21/Vol11N21A11.pdf]

Además, nuestro legislador contempla en los artículos 248 bis y 249 una serie de figuras agravadas en razón de la vinculación entre el beneficio solicitado o aceptado y la conducta que debe llevar a cabo el funcionario. Así, si en la figura básica la prohibición está vinculada a la actuación propia del cargo, en las siguientes hipótesis se prohíbe tal vinculación con la omisión de un acto debido, con la infracción de deberes de su cargo ${ }^{55}$ o por el hecho de que tal ventaja esté asociada a ejercer influencia en otro empleado público, con el fin de que éste último decida en forma tal que pueda beneficiar a un tercero. Por último, la hipótesis de mayor gravedad está vinculada a la obtención o solicitud de beneficios para que el funcionario respectivo cometa alguno de los que se conocen como "delitos funcionarios 56 ".

Varios aspectos de esta figura no resultan problemáticos. Si el acto corrupto está caracterizado, en parte, por la priorización de intereses secundarios que se encuentran en conflicto con los intereses que debieran tenerse por prioritarios, se entiende, que tanto aceptando como solicitando el respectivo beneficio en cualquiera de las situaciones que describen los respectivos tipos penales, se está comunicando en forma categórica que priman, para éste, los intereses incorrectos. También se entiende, sin problema, la necesidad de que se sancione el cohecho subsiguiente, ya que el momento del pago es irrelevante si la decisión del funcionario fue tomada debido al beneficio que se recibirá, o incluso porque en futuras decisiones podría exigirse el mismo beneficio (es decir, igualmente resulta incompatible con los intereses del representado).

Con todo, sí puede resultar problemática la vinculación necesaria que debiera presentarse entre el beneficio obtenido (o solicitado) y la clase de conducta asociada que debe llevar a cabo el funcionario en razón del primero. En este sentido, y a través del concepto de corrupción, se pueden clarificar algunos problemas interpretativos relativos a la exigencia

de la decisión de utilizar la voz "beneficio económico", a partir de la dictación de la ley No 19.645, en vez de los términos "dádiva" y "promesa". Si bien no parece discutible desde la perspectiva interpretativa del tipo penal, si puede discutirse si tal decisión resulta satisfactoria desde una perspectiva político-criminal. Además, debe quedar en claro que no se está diciendo que la delimitación de lo que se entiende por "beneficio económico" no pueda ser objeto de debate (relativo a su extensión) solo se dice que ya no parece discutible que la ventaja debe ser de contenido económico y no de otra naturaleza. Al respecto, en detalle, OLIVER, “Aproximación", cit. nota $n^{\circ} 35$, p. 96. Como señala el autor, esto no significa "que no se sancione al funcionario que solicite un favor de naturaleza sexual a quien tenga algún asunto que dependa de la resolución de aquél. Se le castiga, pero no a título de cohecho, sino como una forma de abuso contra particulares (art. 258 del Código Penal)". Sin embargo, se debe tomar en consideración que hay casos que no podrían ser sancionados como un abuso de particulares y que responderían igualmente a los atributos de la "corrupción". Piénsese, por ejemplo, en el caso de un sujeto que ofrece servicios sexuales al funcionario público, el que accede, para que lleve a cabo las labores propias de su cargo, generando una ventaja injustificada en relación al resto de los potenciales beneficiarios.

${ }^{55}$ De acuerdo a lo sostenido por OLIVER, "Aproximación”, cit. nota n³5, pp. 103-104, un funcionario “infringe los deberes de su cargo al ejecutar un acto, cuando con su realización contraviene las disposiciones que regulan el desarrollo de las funciones propias del cargo o del servicio al que pertenece". Tal infracción, como señala el autor, no solo es posible de presentarse en el "ejercicio de su actividad reglada, sino también dentro de su actividad discrecional".

${ }^{56}$ En estricto rigor, se sanciona el solicitar o aceptar un beneficio económico, para sí o para un tercero, con el fin de cometer algunos de los delitos previstos en el título $\mathrm{V}$ o en el párrafo 4 del Título III del Libro segundo del Código penal. 
ARTAZA, Osvaldo. "La utilidad del concepto de corrupción de cara a la delimitación de la conducta típica en el delito de cohecho".

de que el beneficio esté vinculado a ejecutar labores propias del cargo, omitir o infringir deberes de su cargo, o cometer determinados delitos funcionarios ${ }^{57}$.

Si se observa bien, en los casos en que el legislador utiliza expresiones como "ejecutar o haber ejecutado actos propios del cargo", u "omitir o haber omitido un acto debido propio de su cargo", resultaría central para la configuración de la conducta típica constatar que el agente ha actuado con infracción de sus deberes como representante en el marco de su relación con terceros. Es decir, abusa de su poder decisorio concreto o específico emanado de su esfera de atribuciones, ya sea priorizando intereses incompatibles (beneficio propio) para condicionar su actividad debida o, por el contrario, para no llevar a cabo la misma.

El problema que se puede plantear está dado más bien por la interpretación que se le debiera otorgar a la expresión "infracción de los deberes del cargo", contenida en el art. 248 bis del Código penal.

Para clarificar esta cuestión podemos analizar casos como el siguiente: Un funcionario que no es competente del resguardo de la información confidencial de un servicio público, aprovecha su condición de tal y obtiene tal información para entregársela a un tercero a cambio de una suma de dinero que le ofreció con anterioridad. En este caso el sujeto ejecuta una conducta indebida que, si bien no corresponde a su ámbito de competencia específico, habría sido facilitada por su condición de empleado público. Se podría llegar a pensar que la infracción de los deberes de su cargo vendría dada por el comportamiento desleal para con su institución, y de esta manera se podría incluir en el tipo penal respectivo ciertos casos de vulneraciones de deberes generales de probidad propios del sector público, cuando se lleven a cabo mediante la solicitud o aceptación de un beneficio económico ${ }^{58}$.

\footnotetext{
${ }^{57}$ En lo que alcanzo a ver, este problema se ha planteado por nuestra doctrina a propósito de la extensión que se le debiera asignar a la voz "acto propio del cargo" contenido en la figura básica del artículo 248. Por ejemplo, Oliver sostiene que el problema a resolver es si ésta categoría puede ser interpretada en un sentido amplio, incluyendo los actos cuya comisión ha resultado facilitada por su condición de funcionario, pese a no pertenecer "a la esfera de atribuciones del empleado" o si debe interpretarse en un sentido restringido, que incluya exclusivamente aquello que responda a las competencias específicas del funcionario, OLIVER, "Aproximación", cit. nota $\mathrm{n}^{\circ} 35$, pp. 100-101. Es importante clarificar que tal problema lo plantea en referencia a la discusión de la doctrina española, anterior a la modificación operada por la Ley Orgánica $5 / 2010$, a propósito de la interpretación del término "actos relativos al cargo". Señala, además, que la posición restrictiva, de la doctrina española, es aquella que sostiene que "por actos propios del cargo del funcionario público deben entenderse sólo aquellos cuya realización obedece al ejercicio de las funciones públicas, debiendo descartarse los actos que no pertenecen a la esfera de las atribuciones del empleado, pero cuya comisión resulta facilitada por su condición de tal". La postura "amplia" comprende aquellos actos que "guarden relación con las actividades públicas que éste realiza, pudiendo ejecutarlos con facilidad por la función que desempeña, pero sin que sea necesario que su ejecución corresponda específicamente al ámbito de competencia". De acuerdo a lo señalado por el autor, solo la opción restrictiva sería correcta debido a que no podría considerarse seriamente como acto propio del cargo aquellos actos "cuya realización pueda verse facilitada por su calidad de tal".

${ }^{58} \mathrm{Si}$ bien es cierto no es el propósito de este trabajo ahondar en los problemas interpretativos que se han presentado en el marco de la solución de casos concretos por nuestros tribunales de justicia, puede consultarse, como caso paradigmático, la Sentencia Corte Suprema, Rol 2560-2013, 13 de junio de 2013. La discusión se remitió a la distinción entre deberes del cargo y deberes de probidad institucionales propios de todos los funcionarios de la institución y no del "cargo". La Corte Suprema resuelve, en definitiva, que lo sancionado por el tipo penal es el ofrecimiento de beneficios económicos para la infracción de deberes
} 
Polít. crim. Vol. 11, No 21 (Julio 2016), Art. 11, pp. 307-339.

[http://www.politicacriminal.cl/Vol_11/n_21/Vol11N21A11.pdf]

Con todo, tal solución debe ser puesta en duda si aceptamos que la corrupción es la forma de agresión del tipo penal en comento. Para que estemos frente a un acto de corrupción se debe constatar que se trata de un acto del agente en el marco de sus funciones de representación, y no de aquellas en que, si bien actúa en forma incompatible con los intereses de la institución a la que pertenece, no lo hace a través de un abuso de su esfera de competencias específica ${ }^{59}$.

Un funcionario puede actuar en forma incompatible con ciertos intereses institucionales, por ejemplo de lealtad o de corrección, a través de un aprovechamiento de las condiciones aparejadas a su calidad, sin que al mismo tiempo esté abusando de su poder decisorio. Si bien es cierto que tales deberes de probidad obligarían a todos los funcionarios, su afectación solo sería relevante una vez que se constata que el funcionario actuaba como representante, y no como mero externo que se aprovecha de determinada situación de facto para llevar a cabo la conducta en particular ${ }^{60}$.

En suma, para la resolución de problemas como el anteriormente planteado, parece ser útil la estructura de la corrupción propuesta. A partir de ésta se podría concluir que no toda conducta que suponga infracción de deberes generales dirigidos a los funcionarios públicos, aun en caso de hacerlo para beneficiarse económicamente, satisfaría los elementos del tipo objetivo.

\subsubsection{La incompatibilidad de la actuación del representante.}

Un segundo elemento que debe ser tenido en cuenta a la hora de establecer si la conducta en particular se trata o no de un acto de corrupción es su carácter de incompatible con los intereses declarados por el representado. En el fondo, este requisito no es más que una consecuencia de que uno de los integrantes de tal relación sea un "encargado" o "representante". Con todo, hay una serie de aspectos problemáticos relativos a la delimitación de la conducta típica en el delito de cohecho que podrían ser analizados a partir de tal exigencia.

propios del cargo y no la mera solicitud para infringir deberes de probidad que tienen todos los funcionarios públicos.

${ }^{59}$ En el ámbito comparado resulta necesario destacar que la doctrina mayoritaria española sostendría que bastaría, para la configuración de la conducta típica que el funcionario actúe en contra de su "competencia genérica", es decir, no es necesario que los actos "sean de las específicamente adjudicadas en el reparto interno de sus funciones dentro de la Administración". La diferencia que se presenta con nuestro tipo penal, es que el art. 420 del Código penal español sanciona los casos en que el beneficio se solicite o acepte para "realizar en el ejercicio de su cargo un acto contrario a los deberes inherentes al mismo...". Al respecto, MIR PUIG, “Artículos 404-445”, cit. nota n' 47, p. 1411.

${ }^{60}$ Es importante, eso sí, considerar un caso que debe ser entendido como una excepción, esto es, el de la hipótesis contenida en el inc. $2^{\circ}$ del art. 248 bis consistente en "ejercer influencia en otro empleado público con el fin de obtener de éste una decisión que pueda generar un provecho para un tercero interesado". Como se advirtió con anterioridad, no es posible ahondar en todos los aspectos relevantes del delito de cohecho en esta ocasión. Una de estas particularidades, que deberá dejarse para una investigación en particular, es justamente los casos conocidos como "tráfico de influencias", ya que quien actúa como representante en el marco de la toma de decisión particular no es el mismo que obra priorizando un interés secundario. 
ARTAZA, Osvaldo. "La utilidad del concepto de corrupción de cara a la delimitación de la conducta típica en el delito de cohecho".

Estos problemas se presentarían porque entre nosotros no solo se sancionan los casos en que se acepta o solicita un beneficio para omitir o infringir deberes del cargo, o por cometer ciertos delitos en particular, casos en que la incompatibilidad de la decisión del funcionario con los intereses que debe representar es clara, sino que también se sancionan los casos en que se solicita $u$ ofrece tal beneficio para ejecutar las labores propias del cargo o por haberlo hecho. Estos son los supuestos que podrían generar algunos problemas en sede de la satisfacción del requisito de la incompatibilidad mencionado.

Para analizar este problema se puede tener en mente un primer grupo de casos, a través del siguiente ejemplo: $\mathrm{X}$, un particular, ofrece a $\mathrm{Y}$, funcionario de una empresa que presta servicios de recolección de basura para la Municipalidad, una suma menor de dinero, en el contexto de las fiestas patrias, como agradecimiento por la labor efectuada durante el año.

Por lo general se asume que tales supuestos no satisfarían los requisitos del tipo objetivo pero en razón de consideraciones muy diversas a las acá planteadas. Así, por ejemplo, Rodríguez Collao y Ossandón Widow, señalan que tales regalos se efectuarían precisamente "por haber ejecutado los actos propios del cargo del empleado..." e incluso con el objeto de que los siga desarrollando a futuro ${ }^{61}$. Sin embargo, y en opinión de los mismos, pese a que tales casos podrían satisfacer las exigencias del tipo objetivo de la figura básica del delito de cohecho el "criterio de la adecuación social" impediría el castigo $^{62}$. En ocasiones ciertos pagos a funcionarios, pese a que no estén autorizados por la normativa respectiva, podrían parecer como tolerados ${ }^{63}$.

Con todo, a partir del análisis de la corrupción propuesto se podría llegar a una solución similar, sin recurrir a elementos externos a la estructura de la conducta típica. La relevancia jurídico penal de tales casos debiera determinarse atendiendo a si la conducta del funcionario supone una actuación incompatible con los intereses del representado, por lo que la conducta del particular debiera ser valorada, como contrapartida, atendiendo a si tales hechos revisten o no de la peligrosidad requerida por el tipo penal.

${ }^{61}$ RODRÍGUEZ COLLAO/OSSANDÓN WIDOW, Delitos contra la función pública, cit. nota ${ }^{\circ}$ 19, p. 335. En sentido similar, ETCHEBERRY, Derecho Penal Parte Especial, cit. nota n 22, p. 256, señala que "estos obsequios de cortesía o agradecimiento se producen después de la actuación funcionaria y sin mediar promesa anterior, lo cual es suficiente para excluirlos de la tipicidad de esta figura. En cambio, los "agradecimientos anticipados" son siempre sospechosos.

${ }^{62}$ En relación a la discusión comparada, ver NIETO MARTÍN, "La corrupción”, cit. nota no 30, pp. 79 y ss., señala que en la doctrina española se han considerado algunas causas de atipicidad centradas en la contraprestación del particular que obedecerían a razones cuantitativas y culturales que podrían "reconducirse a tres figuras penales que con carácter general actúan como causas de atipicidad: la adecuación social (contraprestaciones que responden a usos sociales), la tolerancia (contraprestaciones que no responden a usos sociales, pero que la sociedad y los órganos de persecución penal permiten, "mirando hacia otro lado") y el principio de insignificancia (pequeñas contraprestaciones)". También expresamente MIR PUIG, Carlos, "Artículos 404-445", cit. nota no 47, p. 1408.

${ }^{63}$ Los casos que son tenidos en mente por tal sector de la doctrina son los obsequios entregados en determinadas fechas festivas a funcionarios en agradecimiento por su labor. Excluyen, eso sí, los casos en que es el funcionario quien solicita, aun cuando se trate de beneficios insignificantes, así como las respectivas figuras agravadas por ser incompatibles a las mismas. Al respecto, OLIVER, "Aproximación", cit. nota n 35, p. 98. 
Polít. crim. Vol. 11, No 21 (Julio 2016), Art. 11, pp. 307-339.

[http://www.politicacriminal.cl/Vol_11/n_21/Vol11N21A11.pdf]

Así las cosas, se podría negar la relevancia jurídico penal de aquellos casos en los que el beneficio no pueda ser considerado como un medio funcional idóneo para corromper ${ }^{64}$, es decir, para incidir en que el funcionario decida contra intereses legítimos. A partir de tal criterio se debiera definir si la conducta desplegada por el agente puede ser entendida objetivamente como una razón de peso para que el funcionario actúe en contra de los intereses de quien representa.

En el ejemplo propuesto se puede decir, por las razones ya señaladas, que la vinculación del beneficio económico ofrecido con el deber que debe ser cumplido por el funcionario es sumamente débil. Por lo mismo, la decisión de aceptar el beneficio no puede ser considerada, a su vez, como incompatible con tales intereses.

Pero además, se pueden presentar grupos de casos bastante más complejos debido a la presencia de una vinculación más fuerte entre el beneficio y el comportamiento esperado por parte del funcionario. Este problema será planteado, nuevamente, a través de un supuesto de hecho: Un particular solicita a la policía que escolte por la carretera su vehículo de carga, debido a que por las dimensiones y el peso del mismo la reglamentación respectiva exige tal medida de seguridad. El funcionario de la policía señala que no puede hacerlo hasta dentro de una semana, debido a que en ese momento no tienen suficiente combustible para el trayecto. El particular ofrece el dinero para remediar tal situación, debido a que requiere el traslado en forma urgente, el que solo se puede efectuar con la respectiva escolta.

En caso de que tal funcionario no esté autorizado a solicitar derecho alguno por la prestación se podría concluir que se trataría de un beneficio indebido para un tercero (la misma institución, que se ahorraría el gasto correspondiente y que no puede ser de cargo del beneficiario respectivo). Así las cosas, cabe preguntarse si tal conducta debe ser entendida como un abuso del poder decisorio. Con todo, se trataría de casos en que el beneficio ofrecido más bien permitiría o facilitaría el cumplimiento del interés del representado, por lo que no podría ser considerado, a su vez, como incompatible con el mismo.

Distinto sería el caso en que el particular solicite el mismo servicio a la policía, y el funcionario de turno le señale que lo hará siempre y cuando le entregue una suma de dinero para poder pintar sus dependencias, o le compre un televisor para las oficinas de la institución, y el particular acceda a tal solicitud.

En el primer caso, como ya se señaló, la decisión adoptada por el funcionario, mediada por el beneficio recibido, no puede ser considerada como incompatible con los intereses del representado, en la medida que son estrictamente necesarios para dar cumplimiento a la función respectiva en casos en que no se debiera gravar al beneficiario por la imposibilidad de ejecución por parte de la Administración. En este sentido, el principio de imparcialidad,

\footnotetext{
${ }^{64}$ En este sentido NIETO MARTÍN, "La corrupción”, cit. nota $\mathrm{n}^{\mathrm{o}}$ 30, p. 81, para el cual el criterio fundamental para resolver este problema es de imputación objetiva: lo importante es que la contraprestación ilícita deba tener "capacidad objetiva de corromper".
} 
ARTAZA, Osvaldo. "La utilidad del concepto de corrupción de cara a la delimitación de la conducta típica en el delito de cohecho".

declarado como interés preponderante para guiar la actuación de quien representa al Estado, no se vería afectado ${ }^{65}$.

Con todo, en el segundo caso, la contraprestación sería innecesaria para el cumplimiento de la función en forma debida, y solo podría ser comprendida como una priorización de intereses secundarios privados del representante, pese a que en este caso, y en esto radica la complejidad del mismo, el beneficiado resulte la misma institución representada.

La solución del caso exige tomar en consideración dos aspectos diversos. En primer lugar, que el beneficiado no necesariamente debe ser el funcionario que solicita o acepta, sino que también un tercero, categoría que incluye a la propia institución a la que representa. En segundo lugar, perfectamente se podría estar actuando en contra de los intereses declarados por parte del representado y estar, al mismo tiempo, beneficiándolo económicamente.

En síntesis, lo esencial para la configuración del tipo penal, en lo que respecta a este punto, es el abuso del poder decisorio en los términos ya descritos, sin ser relevante si, en definitiva, la actuación redunda en un beneficio para la institución. Pretender equiparar la compatibilidad de la actuación del representante con la mera obtención de un beneficio por parte del representado, no estaría permitido de cara a los elementos del concepto estudiado.

\subsubsection{El lugar del particular en la estructura relacional de la corrupción.}

En lo que respecta al delito de cohecho cometido por particular, cuya figura básica se sanciona en el artículo 250 del Código penal, deben ser tenidas en cuenta algunas especificidades. Como dispone este precepto, la conducta típica consiste en "ofrecer o consentir en dar a un empleado público un beneficio económico, en provecho de éste o de un tercero, para que realice las acciones o incurra en las omisiones previstas en los artículos 248,248 bis y 249, por haberlas realizado o haber incurrido en ellas ${ }^{66,}$.

La pena asignada al delito sería coherente con la decisión del legislador de diferenciar de acuerdo a la clase de conducta que, en este caso, se solicita a cambio del beneficio o que se

\footnotetext{
${ }^{65} \mathrm{Si}$ bien es cierto este problema no puede ser abordado acá, debido a que se aleja del objeto de estudio, en el ámbito comparado, específicamente en lo que respecta a la criminalización de la corrupción en las transacciones económicas internacionales, se presenta una serie de reflexiones similares a propósito del tratamiento de lo que se conoce como pagos para "facilitar trámites" o "grease payments", los que bajo ciertas condiciones, y solo en algunos ordenamientos jurídicos, no resultan prohibidos. Por tal motivo se entiende que en éste ámbito se propongan una serie de criterios para delimitar qué se entenderá por tal clase de gastos y cuándo debe entenderse que se sobrepasa lo permitido. Especialmente relevante es el tratamiento que se le ha otorgado a este fenómeno a propósito del análisis de las Foreign Corrupt Practices Act estadounidense.Al respecto ver, en detalle, NICHOLS, Philip M., “Are Facilitating Payments Legal?”, Virginia Journal of International Law, Vol. 54 (2013), pp. 129 y ss.; BUNKER, Randall B.; CASEY K., Michael, "Facilitating Payments versus Bribes: Are We Sending Conflicting Ethical Signals in Accounting Education?", International Journal of Business and Social Science, Vol. 3, $\mathrm{N}^{\circ} 8$ (2012), pp. 48 y ss. El tema es bastante complejo de abordar ya que no existe una forma unitaria de tratamiento. Por ejemplo la Serious Fraud Office, a través de su "Enforcement of the United Kingdom's Bribery Act- Facilitation Payments", de 6 de diciembre de 2012, incluye expresamente dentro la prohibición de soborno a funcionario público los "facilitation payments".

66 OLIVER, “Aproximación”, cit. nota n³5, p. 107.
} 
Polít. crim. Vol. 11, No 21 (Julio 2016), Art. 11, pp. 307-339.

[http://www.politicacriminal.cl/Vol_11/n_21/Vol11N21A11.pdf]

accede a dar. Así, la hipótesis de menor gravedad es la de aceptar dar tal beneficio para los casos en que sea el funcionario quien lo solicite para ejecutar o haber ejecutado un acto propio de su cargo. Se agrava la pena, contemplándose desde ahora la pena privativa de libertad, para los casos en que sea el particular el que ofrece el beneficio para que se ejecute o por haberse ejecutado las labores propias del cargo ${ }^{67}$. Tal diferencia de penalidad se repite incluso en el resto de las figuras, es decir, en la prohibición de ofrecer o consentir en dar un beneficio para que se lleven a cabo las conductas contenidas en el art. 248 bis del CP (para omitir deberes u obrar con infracción de los mismos) y el 249 del CP (comisión de determinados delitos). En ambos casos se contempla un rango mayor de penalidad para el caso del ofrecimiento que para el de consentir ${ }^{68}$.

Desde la perspectiva de la legitimidad de la sanción al particular, y como se dijo anteriormente, se debe entender que el tipo penal no protege deberes de lealtad o de fidelidad del funcionario para con el Estado, ya que si así fuera la misma se podría poner en duda si se entiende que no recaen tales deberes en el particular. No sucede lo mismo si se acepta que el tipo penal protege determinadas expectativas de participación en ciertas condiciones de igualdad. Parece perfectamente legítimo dirigir a los ciudadanos prohibiciones destinadas a evitar que tergiversen o cooperen con la tergiversación de tales reglas del juego.

Con todo, algunos supuestos de intervención de particulares podrían ser considerados como de difícil solución en lo que respecta al tratamiento que debiera otorgarse a éste. Como ha advertido la doctrina comparada especializada, el ámbito más problemático de esta figura estaría dado por las hipótesis de cohecho de particular en su modalidad pasiva. Es decir, los casos en que el particular accede a la solicitud del funcionario ${ }^{69}$, ya que podrían presentarse

\footnotetext{
${ }^{67}$ En relación a tales hipótesis debe destacarse la denuncia efectuada hace un tiempo por parte de nuestra doctrina, relativa a una eventual laguna de punibilidad para los casos en que el beneficio no se solicite o acepte para que el funcionario ejecute u omita un acto (o por haberlo ejecutado u omitido), sino que esté vinculado al retraso de determinada actuación. Reconocen, eso sí, que en ciertas ocasiones tales dilaciones podrían ser entendidas como una infracción a los deberes propios del cargo, lo que no sería posible de plantear, en todo caso, como una regla general. Lo mismo sucedería en los casos de la figura agravada del artículo 249 del Código penal que no contemplaría dentro de la conducta típica el solicitar o aceptar un beneficio económico por el hecho de ya haber cometido cualquiera de los delitos señalados. Al respecto, OLIVER, “Aproximación”, cit. nota n 35, p. 105.

${ }^{68}$ Al respecto, OLIVER, “Aproximación”, cit. nota $n^{\circ} 35$, p. 109, sostiene que otro elemento problemático que presenta este artículo en relación a la pena a aplicar dice relación con la evidente desproporcionalidad que existiría entre los casos en que es el particular el que ofrece o consiente en dar un beneficio por la comisión de algunos de los delitos señalados en el art. 249 y la pena que se le podría imponer al funcionario que solicita o acepta el beneficio para llevar a cabo tales conductas. En el caso de que en definitiva no cometa el delito funcionarial solo se le podría sancionar con penas de multa e inhabilitación mientras que al particular incluso con pena privativa de libertad.

${ }^{69}$ Así, por ejemplo, en el ámbito español, en la actualidad se sanciona al particular con la misma pena que al funcionario en caso de "atender el particular la solicitud del funcionario entregando dádiva o retribución". Como describe MIR PUIG, “Artículos 404-445”, cit. nota n ${ }^{\circ}$ 47, p. 1422, previo a la última modificación del Código penal español, el art. 423.2 preveía "la imposición de la pena inferior en grado a las previstas para los funcionarios". Sostiene, además, que tal modificación es discutible "pues hay razones para sostener que la pena del particular que atiende a la solicitud del funcionario sin haberla inducido... debería ser menor, por la debilidad del particular frente al funcionario público, pudiendo temer aquél que el funcionario le perjudique de no acceder a su solicitud”. Como explica NIETO MARTÍN, “La corrupción”, cit. nota n 30, p. 68, en la
} 
ARTAZA, Osvaldo. "La utilidad del concepto de corrupción de cara a la delimitación de la conducta típica en el delito de cohecho".

dificultades a la hora de delimitar los casos de corrupción de los casos en que la conducta del particular, que acepta, no debiera ser considerada como tal.

Como se defenderá acá, para poder sancionar al particular en las hipótesis detectadas, debiera poder considerársele como un partícipe de la estructura relacional propia de la corrupción. La participación en las relaciones de ésta supondría una interacción entre los partícipes bajo ciertas condiciones de equiparidad o igualdad. De esta manera se entiende, que cierta doctrina se sirva de la estructura de la "compraventa de la función pública" para graficar una de las principales características del cohecho ${ }^{70}$. Un desarrollo adecuado de este problema pasaría por diferenciar los casos en que el funcionario y el particular actuarían en calidad de oferente y aceptante, de aquellos en que lo anterior no ocurriría.

Lo anteriormente señalado sería fundamental debido a que la conducta de acceder a entregar el beneficio ilegítimo sería atípica en los casos en que el particular debiese ser considerado como víctima de un delito cometido por un funcionario público, especialmente el contenido en el artículo 241 del CP, que sanciona al empleado público que en forma directa o indirecta "exigiere" al particular un beneficio económico ilícito para ejecutar un acto propio del cargo.

Entre nosotros Rodríguez Collao y Ossandón Widow, han señalado que el delito contenido en el art. 241 del CP tiene como fin la protección del particular frente a abusos por parte de los funcionarios ${ }^{71}$. Según tal postura, el abuso podría verificarse de dos formas diversas, ya sea mediante el engaño, esto es, aprovechándose de la "apariencia de legalidad creada por el cargo de quien exige derechos no debidos realmente", o bien mediante lo que definen como un "cierto carácter de imposición o superioridad"72.

La conducta típica consistiría en "exigir" tales derechos o beneficio económico, lo que "generalmente se ha entendido como algo más que "pedir", sin llegar a significar coacción o fuerza ${ }^{73}$ ". Lo anterior vendría refrendado por el hecho que el verbo exigir podría ser interpretado, entre otras formas, como "pedir imperiosamente algo". En suma, lo que caracterizaría el delito de exacción ilegal sería que la "exigencia al particular ha de realizarse en un contexto caracterizado por la posición de superioridad del funcionario, la confianza que generalmente se exige al particular respecto al actuar administrativo y la apariencia de legalidad ${ }^{74,}$. Para los efectos del problema planteado se debiera determinar si

interpretación del antiguo Código penal se consideró por cierta doctrina que para los casos de cohecho impropio, en lo que respecta al particular, esta conducta debía quedar impune, lo que se debería a una "concepción extorsiva" de esta modalidad.

${ }^{70} \mathrm{Al}$ respecto, por ejemplo, NIETO MARTÍN, “La corrupción”, cit. nota n 30, p. 70.

${ }^{71}$ Este tipo penal ha sido definido como una exacción ilegal por tales autores. No así, POLITOFF/MATUS; RAMÍREZ, Lecciones de derecho penal chileno, cit. nota ${ }^{\circ} 23$, pp. 503-504, los que se refieren a este tipo penal como delito de concusión (o cohecho pasivo propio agravado del art. $241 \mathrm{del} \mathrm{CP}$ ). Al abordarlo dan cuenta, principalmente, del nulo contenido de esta figura como delito independiente luego de la modificación del delito de cohecho que incluye incluso la "mera solicitación sin aceptación por parte del particular (art. 248)".

${ }^{72}$ RODRÍGUEZ COLLAO/OSSANDÓN WIDOW, Delitos contra la función pública, cit. nota n ${ }^{\circ} 19$, p. 432.

${ }^{73}$ RODRÍGUEZ COLLAO/OSSANDÓN WIDOW, Delitos contra la función pública, cit. nota n ${ }^{\circ} 19$, p. 432.

${ }^{74}$ RODRÍGUEZ COLLAO/OSSANDÓN WIDOW, Delitos contra la función pública, cit. nota n $19, \mathrm{p} .433$. 
Polít. crim. Vol. 11, No 21 (Julio 2016), Art. 11, pp. 307-339.

[http://www.politicacriminal.cl/Vol_11/n_21/Vol11N21A11.pdf]

la conducta del funcionario se "mueve entre la imposición y el engaño", ya que los casos en que no fuera así se configuraría la hipótesis contenida en el art. 248 del CP y, por ende, el particular podría ser sancionado de acuerdo a lo establecido por el art. 250.

A través del análisis de los elementos de la corrupción se podría clarificar este problema. Se podría concluir, en primer lugar, que los casos en que el particular paga debido a que actúa bajo error acerca de la licitud u obligatoriedad del mismo, no podrían ser considerados problemáticos, ya que para estar frente a un acto de corrupción se requeriría de una relación de cierta equiparidad entre el representante y el tercero que acepta el ofrecimiento del primero. Tal relación no se concretaría en esta primera hipótesis, debido al déficit de información con el que actúa el particular.

Ahora, y de acuerdo a tales autores, para que se configure el delito de exacción ilegal no bastaría un mero pedir, sino que algo más, pero que tampoco debiera alcanzar el nivel de la coacción. Es decir, en un extremo parece claro que, de acuerdo al concepto de corrupción defendido, el particular coaccionado no puede ser considerado como un verdadero aceptante.

Pero, en el otro extremo, es razonable sostener que el acceder a una mera solicitud sí satisfaría los requisitos propios de la corrupción, en la medida que se entienda la solicitud como una oferta que pudiera ser rechazada por el destinatario. Si el particular acepta estaría colaborando con la degeneración de las pautas ideales que deben regir la actuación del representante, infringiendo así deberes que se dirigen al mismo particular.

Con todo, entre ambos extremos se podrían identificar zonas de mayor complejidad. Tales casos estarían dados por el tránsito entre el mero solicitar y lo que debiera entenderse por "exigir". De acuerdo a la posición en comento el verbo típico "exigir" se vincularía a un contexto de superioridad del funcionario público. Con todo, el mismo resulta muy difuso y no permitiría diferenciar adecuadamente los casos de "solicitud" de los de "exigencia". En el fondo, el hecho que la prestación esperada dependa del poder decisorio del funcionario podría dar a entender que siempre se encontraría en una situación de superioridad. Obviamente tal conclusión dejaría sin contendido el deber dirigido al ciudadano, consagrado en el artículo 250 del $\mathrm{CP}$, de no ceder ante cierto margen de peticiones emanadas de los funcionarios públicos.

Con el objeto de ahondar en este problema de delimitación podría ser útil recurrir al método comparado, con el solo objeto de identificar esfuerzos argumentativos para distinguir los casos en que el particular, en definitiva, no debiera ser sancionado por un acto de corrupción.

Así, y solo a modo de ejemplo, se dará cuenta en forma muy breve de ciertos intentos de solución de problema de la doctrina italiana, en la medida que se podrían extraer criterios que resultarían del todo pertinentes ${ }^{75}$. Viganò, en forma reciente, señala que se debieran

\footnotetext{
${ }^{75}$ Señalo que la discusión italiana sería plenamente aplicable solamente en la medida que se pretenda determinar las razones por las cuales la conducta del particular que acepta otorgar una ventaja indebida no debiera ser catalogada como corrupción. Es importante tomar en cuenta algunas particularidades de tal
} 
ARTAZA, Osvaldo. "La utilidad del concepto de corrupción de cara a la delimitación de la conducta típica en el delito de cohecho".

considerar tres hipótesis diversas ${ }^{76}$. En primer lugar, no cabría duda que el particular no debería ser sancionado por un acto de corrupción en los casos en que acepte otorgar el beneficio indebido en razón de una amenaza de infringirle un daño o mal absolutamente ajeno al poder conferido al funcionario (como por ejemplo la amenaza de causarle la muerte o un mal a su familia).

En segundo lugar, podrían ser analizados los casos en que el particular accede a la solicitud del funcionario, debido a la amenaza de causarle un mal vinculado a un abuso del poder conferido al empleado (como, por ejemplo, negar cierta prestación a la cual el particular tiene derecho o retrasar indefinidamente un beneficio, etc.).

Para tales casos, la tendencia internacional sería mantener la sanción al particular, ya que lo que se espera de éste es que denuncie el hecho a las autoridades y que no ceda a la presión del funcionario. Eso sí, se excluiría la sanción cuando el particular se encuentre en un verdadero estado de necesidad que solo pueda subsanar a través de tal prestación.

Por último, el autor señala que no habría problema alguno en justificar la sanción cuando el particular cede a la solicitud del funcionario con el único propósito de obtener una ventaja indebida (por ejemplo, ver mejorada su situación en relación al resto de los ciudadanos, y no con el propósito de evitar un daño injusto).

En suma, parece sumamente razonable partir de la base que para determinar si se está frente a un acto de corrupción, se debiera atender a la posición en la que se encuentra el $\operatorname{particular}^{77}$. La estructura relación del concepto estudiado exigiría que ambos se encuentren en condiciones de igualdad o paridad.

discusión con el objeto de evitar confusiones. La misma se ha desarrollado a propósito de la distinción entre el delito de concussione y el de corruzione, ya que el Código penal italiano sanciona en su artículo 317, como delito de concusión, al funcionario público o encargado de un servicio público que abusando de su calidad o de su poder constriña o induzca a otro a dar o prometer a él o a un tercero dinero u otra ventaja en forma indebida. Ver en detalle, DOLCINI, Emilio; MARINUCCI, Giorgio, Codice Penale Commentato. Artt. 1 384bis, II Edizione, Italia: Edit. Ipsoa, 2006, pp. 2221-2224, los que distinguen entre tres teorías para resolver tal problema: a) La teoría de la iniciativa; b) la teoría de la posición o acuerdo de la voluntad y; c) teoría del daño o de la ventaja. En ambos delitos el particular podría terminar aceptando entregar una ventaja ilícita al funcionario quien, a través de su solicitud, abusa de su función pública.

${ }^{76}$ VIGANÒ, Francesco, "I delitti di corruzione nell'ordinamento italiano: qualche considerazione sulle riforme già fatte, e su quel che resta da fare", Diritto Penale Contemporaneo, 3-4 (2014), pp. 18-19, disponible en web: http://www.penalecontemporaneo.it/foto/3364DPC Trim 3-4_2014.pdf [visitado el 29.12.2015]. Este autor describe principalmente la solución que ha sido propuesta por Vincenzo Mongillo.

${ }^{77}$ Así, en forma expresa para diferenciar la corruzione de la concussione, AA.VV, Diritto penale, Parte Generale e Speciale 3/2 (a cargo de PEZZANO, Roco), Italia: Edizioni Giuridiche Simone, XVI edición, 2012, pp. 372-373. Esta no es, eso sí, la única forma como se ha propuesta diferenciar ambos delitos, por ejemplo, SGUBBI, Filippo, "Los delitos contra la administración pública. Reflexiones dogmáticas y político criminales a la luz de la evolución del Derecho penal italiano", PALMA, José Manuel (Trad.), Revista Electrónica de Ciencia Penal y Criminología, 02-05 (2000), disponible en web: http://criminet.ugr.es/recpc/recpc_02-05.html [visitado el 29.04.2016], sostiene que en suma la diferencia no se determina en la práctica en la conducta típica, sino más bien en el "estado de coartación de la voluntad del particular, esto es, un elemento de naturaleza psicológica de difícil determinación jurídica”. Con todo, llama la atención que igualmente este estado impediría asegurar que ambas partes están en igualdad de condiciones. 
Polít. crim. Vol. 11, No 21 (Julio 2016), Art. 11, pp. 307-339.

[http://www.politicacriminal.cl/Vol_11/n_21/Vol11N21A11.pdf]

Si bien es cierto este problema debe ser desarrollado con mayor profundidad, se podrían identificar casos que pudieran ser entendidos como actos de abuso y no como parte de un acto de corrupción. Así, y solo a modo de ejemplo, en los casos en que el funcionario genere a través de la dilación o denegación de un servicio, situaciones en que se pueda causar un daño injusto al particular ${ }^{78}$ y que no puedan ser remediadas efectivamente por una vía alternativa, debieran ser entendidas como un acto de abuso y no un acto de corrupción $^{79}$. El criterio central vendría dado por la detección de situaciones en que no se debiera exigir al particular que se niegue a satisfacer las pretensiones del funcionario ${ }^{80}$.

\section{Conclusión}

Si bien el concepto de corrupción resulta sumamente vago, una delimitación precisa del mismo podría ser útil para efectos jurídico penales. Para tales efectos, se deben concretar los atributos que deben ser predicados de una conducta para ser calificada como corrupta.

Como se pudo advertir a lo largo del trabajo, este concepto puede ser utilizado tanto en un sentido amplio como en otro restringido. El uso amplio del concepto presentaría la desventaja de no dar cuenta en forma precisa de las propiedades de una conducta en forma que sea aprovechable para la dogmática jurídico penal. Por lo mismo, parece preferible atender al uso o sentido restrictivo del concepto, de acuerdo con el cual debiera ser entendido como una forma de agresión específica a diversos intereses. Ésta se caracterizaría por tratarse de un abuso del poder decisorio por parte de un representante, esto es, la priorización de intereses incompatibles con los del representado, en el marco de la representación de tales intereses frente a terceros.

De esta manera, y luego de constatar que en nuestro ordenamiento jurídico penal el tipo de cohecho puede ser entendido sin duda alguna como un acto de corrupción, se abordaron

\footnotetext{
${ }^{78}$ En la doctrina italiana Viganó ha propuesto, por ejemplo, que se incluya una cláusula específica en el tipo penal que evite que se sancione a los particulares, en los casos en que se vean obligados a pagar con el objeto de evitar un daño injusto. VIGANÒ, "I delitti di corruzione", cit. nota $n^{\circ} 76$, p. 19.

${ }^{79}$ Un aspecto que sí debe ser desarrollado a futuro es el criterio de la prevención del daño por vías alternativas. Me refiero a casos en que, por ejemplo, no se pueda recurrir a otro funcionario que preste el mismo servicio o casos en que la denuncia de tal amenaza a las autoridades no parezca como efectiva para evitar el daño injusto.

${ }^{80}$ Un criterio similar se extraería de la práctica estadounidense relativa a la sanción por soborno a funcionario público extranjero en el ámbito de las transacciones comerciales internacionales, en la medida que otorga criterios para establecer cuándo se presentarían casos de "verdadera extorsión", los que justamente se excluirían del ámbito de prohibición de las Foreign Corrupt Practices Act. De acuerdo a fallos emblemáticos, como United States v. Kozeny, sería muy distinto acceder a pagar a un funcionario extranjero con el objeto de poder entrar a competir a un mercado o para obtener un contrato, que pagar para evitar, por ejemplo, que se dinamite una plataforma petrolífera, caso que debiera ser considerado como "verdadera extorsión". De acuerdo al razonamiento del tribunal el motivo por el cual se podría sancionar en el primer caso y no en el segundo, es que quien paga no podría sostener que no tuvo la intención de sobornar al funcionario ya que tomó una "decisión consciente" de pagarle. Es decir, en el primer ejemplo, quien paga "podría haber dado media vuelta y alejarse del lugar", lo que no sucede en el segundo caso. Por ende, quien actúa coaccionado actúa por tal motivo y no en forma corrupta. El caso puede consultarse en la web: http://www.justice.gov/sites/default/files/criminal-fraud/legacy/2012/06/01/2011-12-14-kozenyv-opinionsecond-circuit.pdf. [ visitado el 20.12.15].
} 
ARTAZA, Osvaldo. "La utilidad del concepto de corrupción de cara a la delimitación de la conducta típica en el delito de cohecho".

una serie de aspectos problemáticos relativos a delimitación de la conducta típica de este delito a partir de los elementos constitutivos de la corrupción.

Para tales efectos, se tomó en consideración las diversas exigencias que provienen de cada uno de los niveles de la estructura relacional de la corrupción, es decir, de la relación que se presenta entre el funcionario público y el Estado, por un lado, y entre el funcionario y el particular, por el otro. A través del análisis del primer nivel detectado, se podrían resolver aquellos problemas que digan relación con la determinación de quiénes pueden actuar como representantes. Asimismo, se podría delimitar la relevancia jurídico penal tanto del comportamiento del funcionario como del particular. Por último, y en lo que respecta a las exigencias propias de la relación entre el funcionario y el particular, se podría determinar cuándo nos enfrentamos a un acto de corrupción y no a un abuso por parte del primero. 
Polít. crim. Vol. 11, № 21 (Julio 2016), Art. 11, pp. 307-339.

[http://www.politicacriminal.cl/Vol_11/n_21/Vol11N21A11.pdf]

\section{BIBLIOGRAFÍA}

AA.VV, Diritto penale, Parte Generale e Speciale 3/2 (a cargo de PEZZANO, Roco), Italia: Edizioni Giuridiche Simone, XVI edición, 2012.

ALCALE SÁNCHEZ, María, "La lucha contra la corrupción en el ámbito supranacional y su incidencia en el código penal español”, Diritto Penale Contemporaneo, 3-4 2014, disponible en web: http://www.penalecontemporaneo.it/foto/3364DPC_Trim_34_2014.pdf [visitado el 29.12.2015].

ARGANDONA, Antonio, "La corrupción y las empresas", Occasional Paper IESE Business School-Universidad de Navarra, OP-07/21 (2007), disponible en web: http://www.iese.edu/research/pdfs/OP-07-21.pdf [visitado el 28.12.2015].

BALMACEDA, Gustavo; CASTRO, Carlos, Corrupción y delitos contra la administración pública. Especial referencia a los delitos de malversación de caudales y fraude al fisco, Santiago: Librotecnia, 2015.

BUNKER, Randall B.; CASEY K., Michael; "Facilitating Payments versus Bribes: Are We Sending Conflicting Ethical Signals in Accounting Education?", International Journal of Business and Social Science, Vol. $3 \mathrm{~N}^{\mathrm{o}} 8$ (2012).

BURKE, Thomas, "The concept of corruption in campaign finance law", Commentary 127 (1997).

CARASSALE, Santiago, “Corrupción”, Eunomía. Revista en Cultura de a Legalidad, № 4 (2013).

CARUSO FONTÁN, María Viviana, "El concepto de corrupción. Su evolución hacia un nuevo delito de fraude en el deporte como forma de corrupción en el sector privado", Foro, Nueva Época, n 9 (2009).

CLARK, Kathleen, "Do we have enough ethics in government yet?: An answer from fiduciary theory", University of Ollinois Law Review, 57 (1996).

DE LA CUESTA ARZAMENDI, José Luis, "Iniciativas Internacionales contra la corrupción", Eguzkilore, № 17 (2003).

, "La corrupción ante el Derecho y la Justicia”, Diario La Ley, № 8153, 2013.

DE LA MATA, Norberto J., “¿Qué interés lesionan las conductas de corrupción?”, Eguzkilore, № 23 (2009).

"El bien jurídico protegido en el delito de cohecho. La necesidad de definir el interés merecedor y necesitado de tutela en cada una de las conductas típicas encuadradas en lo que se conoce, demasiado genéricamente, como ámbito de la corrupción", Revista de Derecho Penal y Criminología, $2^{\mathrm{a}}$ época, № 17 (2006).

DÍAZ Y GARCÍA CONLLEDO, Miguel, "Corrupción y delitos contra la administración pública. Insuficiencias y límites del derecho penal en la lucha contra la corrupción: el ejemplo español", Revista de Derecho, No 7 (2004).

DOLCINI, Emilio; MARINUCCI, Giorgio, Codice Penale Commentato. Artt. 1-384bis, II Edizione, Italia: Edit. Ipsoa (2006).

ETCHEBERRY, Alfredo, Derecho Penal Parte Especial, Tomo IV, Santiago: Editorial Jurídica de Chile, $3^{\mathrm{a}}$ ed., 2010.

GREEN, Stuart, Mentir; hacer trampas y apropiarse de lo ajeno. Una teoría moral de los delitos de cuello blanco, Trad. AGUSTINA SANLLEHÍ, José Ramón; AMORÓS 
ARTAZA, Osvaldo. "La utilidad del concepto de corrupción de cara a la delimitación de la conducta típica en el delito de cohecho".

BAS, Miriam; ORTIZ DE URBINA GIMENO, Iñigo. Madrid, Barcelona, Buenos Aires, Sao Paulo: Marcial Pons, 2013.

GRIFFIN, Lisa Kern, "The Federal Common Law Crime of Corruption", North Carolina Law Review, Vol. 89 (2011).

GUASTINI, Ricardo, Interpretar y argumentar, Trad. ÁLVAREZ MEDINA, Silvana, Madrid: Centro de Estudios Políticos y Constitucionales, 2014.

HOLMES, Leslie, Corruption. A very short introduction; Oxford University Press, United Kingdom, 2015.

JAVATO MARTÍN, Antonio, "El concepto de funcionario y autoridad a efectos penales", Revista Jurídica de Castilla y León, № 23 (2011).

JIMÉNEZ VILLAREJO, Carlos, "Corrupción y sistema político"; Fraude y Corrupción en el Derecho penal económico europeo. Eurodelitos de Corrupción y Fraude; ARROYO ZAPATERO, Luis; NIETO MARTÍN, Adán (Coords.), Cuenca: Ediciones de la Universidad de Castilla-La Mancha, 2006.

KINDHÄUSER, Urs, "Presupuestos de la corrupción punible en el Estado, la economía, y la sociedad. Los delitos de corrupción en el Código Penal Alemán. Los delitos de corrupción en el Código penal alemán”, Trad. GARCÍA CAVERO, Percy, Política Criminal, $\quad \mathrm{n}^{\circ} 3, \quad 2007, \quad \mathrm{~A} 1, \quad$ disponible en web: http://www.politicacriminal.cl/n_03/a_1_3.pdf [visitado el 28.12.2015].

LABATUT GLENA, Gustavo, Derecho Penal, Tomo II, Santiago: Editorial Jurídica de Chile, $7^{\mathrm{a}}$ ed., 1983.

LOMBANA VILLALBA, Jaime, La tipificación del tráfico de influencias y del cohecho en España y en Colombia como forma de prevención de la corrupción pública, Tesis Doctoral, Universidad de León, 2013.

LOWENSTEIN, Daniel H., "Political Bribery and the Intermediate Theory of Politics", UCLA Law Review, Vol. 32 (1984-85).

MAÑALICH, Juan Pablo, "La negociación incompatible como delito de corrupción: estructura típica y criterios de imputación", Revista de Estudios de la Justicia, No23 (2015).

MARTÍNEZ ZORILLA, David, Metodología jurídica y argumentación, Madrid, Barcelona, Buenos Aires, Sao Paulo: Marcial Pons, 2013.

MIR PUIG, Carlos, "Artículos 404-445", en: MIR PUIG, Santiago; CORCOY, Mirentxu, (Dirs.), Comentarios al Código Penal. Reforma LO 1/2015 y LO 2/2015, Valencia: Tirant Lo Blanch, 2015.

NIETO MARTÍN, Adán, "La corrupción en las transacciones comerciales internacionales", en: NIETO MARTÍN, Adán (Coord.), Estudios de Derecho Penal, Universidad Castilla-La Mancha, 2004.

NICHOLS, Philip M., “Are Facilitating Payments Legal?”, Virginia Journal of International Law, Vol. 54 (2013).

OLIVER, Guillermo, "Aproximación al delito de cohecho", Revista de Estudios de la Justicia, $\mathrm{N}^{\circ} 5$ (2004).

POLITOFF, Sergio; MATUS, Jean Pierre; RAMÍREZ, María Cecilia, Lecciones de derecho penal chileno, Santiago: Editorial Jurídica de Chile, $2^{\mathrm{a}}$ ed., 2004. 
Polít. crim. Vol. 11, № 21 (Julio 2016), Art. 11, pp. 307-339.

[http://www.politicacriminal.cl/Vol_11/n_21/Vol11N21A11.pdf]

RODRÍGUEZ COLLAO, José Luis, "Delimitación del concepto penal de corrupción”, Revista de Derecho de la Pontificia Universidad Católica de Valparaíso, XXV (2004).

"La función pública como objeto de tutela penal", Revista de Derecho Pontificia Universidad Católica de Valparaíso, vol. 1, núm. XXVI (2005).

RODRÍGUEZ COLLAO, José Luis; OSSANDÓN WIDOW, Magdalena, Delitos contra la función pública, Santiago: Editorial Jurídica de Chile, $2^{\mathrm{a}}$ ed., 2008.

ROSE, Cecily, International Anti-Corruption Norms. Their creation and influence on domestic legal systems, Oxford: Oxford University Press, 2015.

ROSE-ACKERMAN, Susan, Corruption and Government. Causes, Consequences, and Reform, New York: Cambridge University Press, 1999.

VALEIJE ÁLVAREZ, Inmaculada, "Consideraciones sobre el bien jurídico protegido en el delito de cohecho", Estudios penales y criminológicos, № 18 (1994-95).

VIGANÒ, Francesco, "I delitti di corruzione nell'ordinamento italiano: qualche considerazione sulle riforme già fatte, e su quel che resta da fare", Diritto Penale Contemporaneo, 3-4 (2014), disponible en web: http://www.penalecontemporaneo.it/foto/3364DPC_Trim_3-4_2014.pdf [visitado el 29.12.2015]. 